\title{
TURKISH ADAPTATION OF THE TRANSACTIONAL PRESENCE SCALE AND AN EXAMINATION OF ITS RELATIONSHIP WITH PERCEIVED LEARNING
}

\author{
Gulten KARTAL \\ ORCID: 0000-0003-2923-8955 \\ Anadolu University \\ Eskisehir, TURKEY
}

Received: 13/08/2020 Accepted: 27/08/2020

\begin{abstract}
The main purpose of this study is to establish a valid and reliable Turkish version of the Transactional Presence Scale. The study also aims to determine whether learners' personality structures, age, sex, previous experiences of distance education and perceptions of transactional presence are significant predictors of their perceived learning. The study sample consisted of 467 students who received pedagogical formation training at Sakarya University and agreed to participate in the study. The study used the relational survey model, a general survey model based on the quantitative research paradigm. Data were collected using the Transactional Presence Scale, the Perceived Learning Scale and TIPI-Ten Item Personality Inventory. First, the transactional presence scale was adapted for use in Turkish. Following the validity and reliability tests of the Turkish version of the transactional presence scale, a multiple linear regression analysis was performed to determine whether learners' personality traits, age, sex, previous experience of distance education and perceptions of transactional presence were significant predictors of their perceived learning. The results showed that only institutional transactional presence was a significant predictor of perceived learning. Transactional presence perceptions of the learners in the study explained $29 \%$ of the total variance of their perceived learning.
\end{abstract}

Keywords: transactional presence, the transactional presence scale, big five personality traits, perceived learning, distance education.

\section{INTRODUCTION}

Communication and interaction are central factors in distance learning environments. Moore (1997) called the potential psychological distance that may occur between the learner and the teacher in distance education as transactional distance and listed the components that affect transactional distance as dialogue and structure. Therefore, in these learning environments, the learner does not only have a process of communication and interaction with the teacher. The learner may also have an internal process of communication and interaction with other peer learners, the content, the interface in which the course is delivered, the institution, and even themselves. The perceptions that will occur due to these processes may affect learning outcomes.

In the literature, depending on communication and interaction processes, learner perception is often associated with the concept of presence. In order to produce effective and efficient learning outcomes in a distance education system, internal factors such as learners' perceived learning, including learners' assessment of their own learning, and learners' personality traits can be effective as well as external factors such as learning environments and resources and student support services design. Accordingly, in order to better design distance learning environments and to construct meaningful, efficient and effective learning outcomes by better structuring educational processes, perceived learning, which is an important variable in the field of distance education (Albayrak, Gungoren and Horzum, 2014), and its variables should be examined in addition to the concept of presence. 
According to the distance education literature on presences, the concepts of teaching presence, cognitive presence and social presence are the components of community of inquiry (Garrison, Anderson and Archer, 2000). Following the presences in the community of inquiry framework, Shin proposed the concept of transactional presence (TP) in 2001. TP is composed of teacher, peer student and institution TP components, and it is briefly described as distant learners perceptions of connectedness and availability of these three components within a distance learning system.

In 2001, Shin developed a scale called "the Transactional Presence" to measure TP and its components. Shin (2001) associated TP with the components of learning achievement, satisfaction and intent-to-persist, which are outcomes of distance learning. In Turkey, there are currently no studies about TP. In this respect, it is crucial to adapt the TP scale for use in Turkish and to examine its relationship with perceived learning, which is an important component in distance education. Therefore, the primary aim of this study was to generate a valid and reliable Turkish version of the TP scale. The study also examined whether perceived learning, which is one of the important variables of distance education, is predicted by TP and whether learners' personality traits, age, sex, distance education experiences and perceptions of TP are significant predictors of their perceived learning.

\section{LITERATURE REVIEW}

\section{Transactional Presence Theory}

TP theory was developed by Namin Shin in 2001. TP is "the degree to which a distance student perceives the availability of, and connectedness with, teachers, peer students, and institution" (Shin, 2001, p. 124). TP theory consists of three main components: teacher, peer and institution TP. Each component has two subdimensions: availability and connectedness. Availability means that interpersonal relationships are responsive and that what is needed or desired is available on demand. In other words, it can be expressed as the availability/accessibility of teachers, other peer learners, the institution or the resources and services provided by these components for learners. Connectedness is the belief or feeling that a reciprocal relationship exists between two or more parties (Shin, 2003, p. 71).

Teachers' TP can be expressed as perceived supporters for cognitive learning, peer students' TP can be expressed as perceived supporters for affective learning, and institution's TP can be expressed as perceived interface with support services (Shin, 2001). Institutional TP plays a key role in distance learning. It is also essential that distance learners feel connected to the institution as well as having access to support services. If distance learners do not know about the types of services they can access, they will not be able to utilize these services, which makes it difficult for them to feel connected to the institution, and will be reluctant to express the support they need despite an important task/assignment (Shin, 2001, p. 160). In addition, institution's TP is related to students' expectations from the institution, interaction with the institution or perceptions of the staff working in the institution (Shin, 2001).

Starr-Glass (2013) stated that TP differs from social presence since social presence focuses on social interaction, collaboration and community building while TP focuses only on the concepts of availability and access (p. 124). Perceptual behaviors in an educational environment involve more than the closeness one feels to others and sharing time and space. In this sense, Shin's work brought together the existing perceptions of learners in learning and teaching transactions in an inclusive manner and revealed its sub-dimensions.

\section{Big Five Personality Traits}

The big five personality model is considered to be a comprehensive measure by experts to determine personality traits (Horzum, Ayas and Padır, 2017). The big five model consist of extraversion, agreeableness, conscientiousness, neuroticism and openness to experience personality traits. Extraversion refers to a person's demonstration of sociable, assertive, talkative, active personality characteristics, in other words, not being shy or reserved (Gosling, Rentfrow and Swann Jr, 2003). Agreeableness is about interpersonal relationships and refers to the individual's participation in interpersonal cooperation and the degree to which he or she approves this cooperation (Horzum et al., 2017). Conscientiousness refers to not being careless or impulsive, 
and being hardworking, responsible and self-disciplined (Gosling et al., 2003). Neuroticism refers to emotional instability. Openness to experience indicates the tendency to participate in intellectual activities and to be open to new feelings and thoughts. Openness to experience is, in a way, related to intellectual interest, aesthetic sensitivity, imagination, flexibility and non-traditional attitudes (Horzum et al., 2017).

\section{Perceived Learning}

While actual learning reflects the exchange of information defined by a meticulously prepared learning measurement tool, perceived learning refers to self-reporting, in other words self-reporting based on some internal observations and reflections of the student (Bacon, 2016). Caspi and Blau (2008) defined perceived learning as set of beliefs and feelings one has regarding the learning that has occurred. Perceived learning derives from two sources: cognitive source and socio-emotional source. The cognitive source reflects new knowledge acquired (even if knowledge and meaning are inaccurate), a new meaning acquired, and a perception of other cognitive processes. The socio-emotional source refers to experiences and feelings (e.g. having difficulty or enjoying), interacting (e.g. talking with other students or a teacher), or a sense of innovation/discovery related to the course of study (Caspi and Blau, 2008). Briefly, perceived learning can be defined as one's beliefs about his or her learning based on self-evaluation.

\section{Relevant Studies}

A review of the literature suggests that there are many studies on social, teaching and cognitive presence in relation to the community of inquiry theoretical framework, whereas there are only few studies on TP. In her study of distance education students' perceived learning achievement, satisfaction and intent-to-persist about their courses of study, Shin (2003) stated that distance learners' institution TP predicted all the variables specified for distance learning achievement. She further discussed that peer TP was significantly correlated with satisfaction and intent-to-persist about the course of study variables, and that teacher TP was only associated with the students' perceived learning. In their study of the TP perceptions of two separate groups, Naylor and Wilson (2009) found no differences between online and traditional teaching environments/ tools with respect to student perceptions. The authors also argued that ethnic identity or sex did not play a central role on the students' satisfaction about their communication with peers or faculty. Shin and Chan (2004) investigated the direct and indirect effects of online learning on distance education, and they found a significant relationship between the students' perceptions of institutional presence and satisfaction, persistence in the program, and learning outcomes. In the light of these points, we could suggest that if students feel stronger availability of and connectedness to the agents/institution delivering the course of study, the learning outcomes will be more positive, they will be more satisfied with their learning experiences and they will be more willing to persist in distance learning than those with low institutional presence. In this respect, courses should be tailored to the needs of students, and a distance education program or institution should be in constant communication with its students. Samuel (2015) stated that flexibility, responding to student needs, being available and approachable to students were important factors, and that students needed a variety of types of support, such as direct answers to their questions, as well as linking to content resources and support services, tutorials. Samuel (2015) also found that the faculty participants felt disengaged due to their lack of immediate feedback from their students, lack of physical clues was a major problem for them and this affected their emotional connections with their classes. Poellhuber, Racette and Chirchi (2012) examined students' interests in lessons and their perceptions of teacher and peer TP in videoconference courses offered in three different distance education institutions. The authors found that the videoconference lessons improved perceptions of teacher TP in all the aspects considered in the study, but there were some differences between the institutions regarding teacher and peer students TP. In addition to the effects of the differences in the way teachers conduct their lessons in videoconferencing environments, the difference in interaction needs of the students in these three institutions could have caused the difference among these three institutions. According to Samuel (2015), students need to get feedback from the teacher in order for them to feel connected to the teacher and the lack of feedback also affects their sense of connectedness with the class. Belaja, Boon Sai, and Wei Lin (2012) investigated the relationship between distance learners' perceptions of teacher TP and motivations for learning English through distance education 
and found that distance learners' high levels perceptions of teacher TP were associated with higher levels of intrinsic motivation. Belaja, Boon Sai, and Wei Lin (2012) further argued that teachers needed to recognize learners' needs and expectations regarding the teacher availability and connectedness, which directly affects learners' perceptions of teacher TP. Therefore, according to Belaja, Boon Sai, and Wei Lin (2012), teachers should respond to the e-mails and questions from learners immediately and actively participate in student blogs, chat rooms and discussion forums, and this could increase learners' intrinsic motivation to learn English through distance education.

A review of the literature suggests that there are only few studies on TP perceptions in distance learning environments. Also, these studies mostly address teacher TP. According to the findings obtained from Shin's studies, institutional TP is considered as the most effective factor in these studies. In the relevant literature in Turkish, there is currently no measure for TP and there are currently not any studies to correlate TP with learning outcomes.

\section{METHODS}

\section{Research Model}

Two separate models were used in the study: a scale adaptation model and a relational survey model. The scale adaptation model involved the language translation and equivalence work and validity and reliability tests of the scale. The relational survey model is a research model that aims to determine the presence and/ or degree of changes that occur at the same time between two or more variables (Karasar, 2010. p. 81). The relational survey model was used in this study to examine whether personality structures, age, sex and distance education experiences as well as TP perceptions are predictors of perceived learning, which is an important variable in distance education.

\section{Population and Sample}

The target population of the study was composed of 2.200 students who received pedagogical formation training at Sakarya University Faculty of Education in 2014-2015 spring semester. The study sample initially consisted of 530 students who received pedagogical formation training at the faculty of education for the departments of Turkish Language and Literature, Sociology, Philosophy, Theology and History and who voluntarily completed the scale. The final sample was selected using maximum variation sampling, which is a non-probability sampling technique, to ensure a wide variety of participants. Because 61 participants submitted incomplete scale forms, their forms were not analyzed and the study was finally conducted with 467 participants. The characteristics of the participants are given in Table 1.

Table 1. Demographic characteristics of participants

\begin{tabular}{lllll}
\hline & & $\mathrm{n}$ & $\%$ & Min-Max \\
\hline \multirow{2}{*}{ Sex } & Female & 312 & 67.83 & \\
& Male & 148 & 32.17 & \\
\hline \multirow{2}{*}{ Age } & $21-23$ & 110 & 30.90 & $21-40$ \\
\hline \multirow{2}{*}{ Distance education experience } & $\geq 24$ & 246 & 69.10 & \\
& Yes & 174 & 39.37 & \\
\hline
\end{tabular}

\section{Data Collection Tools}

Data were collected using a 56-item instrument consisting of three measures: the 37-item TP scale developed by Shin (2001) and adapted for use in Turkish by the researcher, the nine-item perceived learning scale developed by Rovai, Wighting, Baker and Grooms (2009) and adapted for use in Turkish by Albayrak, Gungoren and Horzum (2014), and the Ten Item Personality Inventory (TIPI), which is a 10-item scale of 
the big five personality traits scale developed by Rammstedt and John (2007) and adapted for use in Turkish by Horzum, Ayas and Padır (2017). The data collection tool also collected data about the participants' sex, age and previous experiences of distance education.

\section{Perceived Learning Scale}

The Perceived Learning Scale developed by Rovai et al. (2009) and adapted for use in Turkish by Albayrak et al. (2014) was used in the study. The scale is a nine-item scale that consists of three factors for measuring cognitive, affective and psychomotor learning. Items 2 and 7 in the scale are inversely scored. In the original version of the scale, respondents indicate their agreement with each of the statements among the options ranging from "Not at all" (1) to "Very much so" (7). As a result of the confirmatory factor analysis (CFA) conducted by Albayrak et al. (2014), the three-factor structure of the scale was confirmed by the fit values $\mathrm{X}^{2} / \mathrm{sd}=1.43, \mathrm{GFI}=0.94, \mathrm{CFI}=0.96$ and $\mathrm{RMSEA}=0.059$. The item load values of the scale ranged from 0.62 to 0.86 . As a result of the reliability analyzes, the Cronbach's alpha internal consistency coefficient was found to be 0.83 for all the items of the scale, 0.65 for the cognitive learning, 0.66 for the affective learning and 0.72 for the psychomotor learning. These results indicated that the scale could be used as a valid and reliable measure for use in Turkish (Albayrak et al., 2014).

\section{Ten-Item Personality Inventory}

The study also employed the TIPI, which is a 10-item version of the big five personality traits scale developed by Rammstedt and John (2007) and adapted for use in Turkish by Horzum et al. (2017). The scale consists of five dimensions each of which has two items: extraversion, agreeableness, conscientiousness, neuroticism, and openness to experience. As a result of the CFA conducted by Horzum et al. (2017), the validity of the factor structure of the scale was confirmed by the fit values $X^{2}=46.139$, RMSEA $=0.062$, GFI $=0.96$, $\mathrm{AGFI}=0.91, \mathrm{CFI}=0.98, \mathrm{NFI}=0.97$ and $\mathrm{SRMR}=0.035$. The item load values of the scale ranged from 0.706 to 0.946 . As a result of the reliability analyzes, the internal consistency and composite reliability values of the scale were found to be 0.88 and 0.83 respectively for extraversion, 0.81 and 0.73 respectively for agreeableness, 0.90 and 0.85 respectively for conscientiousness, 0.85 and 0.79 respectively for neuroticism, and 0.84 and 0.78 respectively for openness to experience. These results showed that the scale could be used as a valid and reliable measure for use in Turkish culture (Horzum et al., 2017).

\section{Transactional Presence Scale}

The TP scale developed by Shin (2001) was adapted for use in Turkish in this study. Based on the concepts of availability and connectedness, Shin (2001) developed a 64-item TP scale in order to determine the perceptions of distance learners about TP of teacher, other peer learners and the institution as well as their satisfaction and intent-to-persist about the course studied. The original version of the scale included five scales for distance learners' perceptions of teacher, peer and institution presences and their satisfaction and intent-to-persist about the course of study as well as demographic questions. The scale items included expressions such as "I believe" and "I feel" so that respondents" subjective thoughts could be reflected. Responses to the scale items were given on a five-point Likert scale: (1) Strongly Disagree, (2) Disagree, (3) Neutral, (4) Agree, and (5) Strongly Agree. The validity and reliability tests of the scale were conducted with 506 distance learners enrolled at the National Open University of Korea.

Shin (2001) first published the TP scale with a total of 71 items. Among the items, 15 were about learners' perceptions of institution TP of Korea National Open University, 15 were about their perceptions of teacher TP and 15 were about their perceptions of peer students TP. The scale also had eight items about students' experiences with the university to determine their satisfactions and six items were about students' future studies at the university to determine their intent-to-persist in their courses of study. The remaining 12 items were about students' demographic characteristics. Validity and reliability analyzes were performed on 59 items except the last 12 items. First, 59 items were evaluated by experts in the field of distance education. After this step, in order to determine whether each item in the scale reflected the definitions given for the purposes of the study, the items were grouped under relevant themes and evaluated by a total of 10 subject 
experts at different universities, and if all the expert evaluations of an item were $80 \%$ or above, those items were included in the scale. Following all the evaluations and exclusions, a 51-item TP scale was generated for measuring teacher, peer and institution TP and satisfaction and intent-to-persist about the course of study. A pilot study was conducted for the generated scale and, during the pilot study, the scale items were firstly translated from English to Korean and then back to English. For the validity test, exploratory factor analysis (EFA) and varimax rotation were performed. According to the results for the teacher, peer and institution TP scales, the teacher TP scale consisted of three factors. The six items representing Factor 1 represented teacher availability, and Factor 2 and Factor 3 constituted teacher connectedness dimension. A total of three factors were found to explain $60.8 \%$ of the total variance of the teacher TP scale. The peer TP scale had a two-factor structure. Factor 1 represented peer connectedness and Factor 2 represented peer availability, and these two factors accounted for $69.6 \%$ of the total variance in the peer TP scale. The institution TP scale had a threefactor structure like the teacher TP scale. Factor 1 represented institution availability, Factor 2 and Factor 3 represented institution connectedness and explained $65.4 \%$ of the total variance. To summarize, the factor structures of the TP scale developed by Shin (2001) are as follows:

Table 2. Distribution of the sub-dimensions and factors of the TP scale

\begin{tabular}{lll}
\hline & Availability & Connectedness \\
\hline Teacher TP & Factor 1 & Factor 2 + Factor 3 \\
Peer TP & Factor 2 & Factor 1 \\
Institution TP & Factor 1 & Factor 2 + Factor 3 \\
\hline
\end{tabular}

According to the reliability analysis results, the reliability coefficients of the five scales in the TP scale were 0.83 for intent-to-persist/persistence in the course of study, 0.85 for institution TP, 0.88 for teacher TP, 0.94 for peer TP, and 0.94 for satisfaction.

Once the validity and reliability of the 51 -item scale were ensured, by adding 13 more items about respondents' demographic characteristics in accordance with the purposes of her study, Shin (2001) developed a 64-item measure called "the Transactional Presence Questionnaire". The first part of the instrument consisted of 13 items about students' experiences with teachers to determine their perceptions of teacher TP at Korean National Open University. In the second part, there were 13 items about students' experiences with their peers at the university to determine their perceptions of peer TP. Eleven items in the third part were about students' experiences with the institution to determine their perceptions of institution TP. In the fourth part, there were 8 items about students' perceptions of satisfaction and all their experiences at the university. In the fifth section, there were six items about students' future plans at the university in order to determine their intent-to-persist in their courses of study. The last part included 13 items about respondents' demographic characteristics. In line with the purposes of the current study, the first 37 items (items of the first three parts of the scale about teacher, peer and institution TP) of the 64-item TP scale developed by Shin (2001) were selected for use in this study. Items 46 and 47 , the last two items of the scale used in the study for institution TP, are reverse items, so they were included in analyzes after they were reverse coded.

\section{Procedures}

The procedures followed for adapting the TP scale for use in Turkish were performed in two stages. The first stage included English-to-Turkish translation, expert opinions about the face validity and content validity, and linguistic equivalence work. In the second stage, the scale was administered to 467 students, and construct validity, criterion validity and reliability analyzes were performed.

In line with the purposes of this study, the first 37 items of the original version of the TP scale were selected and translated into Turkish by the researcher. The researcher also prepared a form with enough space for each of the original items, the translated items and suggestions for possible revisions. This form also provided "Acceptable", "Unacceptable" and "Acceptable after revision" options and was sent to five faculty members with expertise in educational technology for their comments. The minimum level of agreement adopted was 
$80 \%$ in order for each of the translated items to be accepted. Items under this level were revised in line with the suggestions received. Following the revisions, the scale was sent to the same experts again and, this time, all the items were found to be acceptable.

After ensuring the face validity and content validity of the scale based on expert opinions, the next step was linguistic equivalence work to determine whether the translated version was equivalent to the original scale. For the linguistic equivalence work, both the original scale and the Turkish translated version of the scale were administered 15 days apart to 32 students of Sakarya University Faculty of Education who were fluent in both languages. After that, the correlation between the scores obtained from the two forms was examined. The correlation value between the total scores obtained from the Turkish and English forms of the scale was found to be 0.68 . The correlation coefficients of each item and three factors of the scale are given in Table 3 .

Table 3. Correlation coefficients of the items and sub-factors of the scale

\begin{tabular}{llllll}
\hline Item & $\mathrm{T}$ & Item & $\mathrm{T}$ & Item & $\mathrm{T}$ \\
\hline $\mathrm{m} 1$ & 0.798 & $\mathrm{~m} 14$ & 0.629 & $\mathrm{~m} 27$ & 0.867 \\
$\mathrm{~m} 2$ & 0.813 & $\mathrm{~m} 15$ & 0.793 & $\mathrm{~m} 28$ & 0.702 \\
$\mathrm{~m} 3$ & 0.707 & $\mathrm{~m} 16$ & 0.675 & $\mathrm{~m} 29$ & 0.712 \\
$\mathrm{~m} 4$ & 0.756 & $\mathrm{~m} 17$ & 0.512 & $\mathrm{~m} 30$ & 0.648 \\
$\mathrm{~m} 5$ & 0.708 & $\mathrm{~m} 18$ & 0.724 & $\mathrm{~m} 31$ & 0.471 \\
$\mathrm{~m} 6$ & 0.768 & $\mathrm{~m} 19$ & 0.854 & $\mathrm{~m} 32$ & 0.695 \\
$\mathrm{~m} 7$ & 0.718 & $\mathrm{~m} 20$ & 0.614 & $\mathrm{~m} 33$ & 0.605 \\
$\mathrm{~m} 8$ & 0.727 & $\mathrm{~m} 21$ & 0.656 & $\mathrm{~m} 34$ & 0.811 \\
$\mathrm{~m} 9$ & 0.714 & $\mathrm{~m} 22$ & 0.665 & $\mathrm{~m} 35$ & 0.873 \\
$\mathrm{~m} 10$ & 0.500 & $\mathrm{~m} 23$ & 0.628 & $\mathrm{~m} 36$ & 0.672 \\
$\mathrm{~m} 11$ & $\mathrm{~m} 24$ & 0.584 & $\mathrm{~m} 37$ & 0.672 \\
$\mathrm{~m} 12$ & 0.771 & $\mathrm{~m} 25$ & 0.739 & & 0.600 \\
$\mathrm{~m} 13$ & 0.833 & $\mathrm{~m} 26$ & 0.910 & & \\
Teacher TP & 0.706 & Peer TP & 0.790 & Institution TP & \\
\hline
\end{tabular}

As can be seen in Table 3, there was a medium-to-high significant relationship between the items and subfactors of the original and Turkish-translated versions of the TP scale. As a result, we concluded that the Turkish adapted version of the scale was linguistically equivalent to the original version.

For the construct validity, criterion validity and reliability analyzes in the second stage, the translated version of the scale was voluntarily completed by 467 students who received pedagogical formation training at Sakarya University Faculty of Education for the departments of Turkish Language and Literature, Sociology, Philosophy, Theology and History. In order to examine the construct validity of the scale, the scale structure was examined using EFA. Next, CFA was performed to confirm this structure. For the criterion validity, the relationship between the scores of the TIPI and the scores obtained from the TP scale was examined with Pearson's correlation test. In order to determine the reliability of the scale, Cronbach's alpha internal consistency coefficient was calculated for the three factors in the TP scale. EFA, Pearson's correlation test and reliability analysis were performed using SPSS version 22 and CFA was performed using AMOS version 22.

Also in this study, whether students' personality structure, age, sex, distance education experiences and perceptions of TP were significant predictors of perceived learning were examined using the data collected with the Turkish version of the TP scale, which was already tested for validity and reliability. Multiple linear regression analysis was performed using SPSS version 22.

In this study, assumptions that should be met for multiple linear regression analysis were tested first. The existence of a linear relationship between the result and the predictor variables was checked and shown with a multiple scatter plot (Figure 1) and single scatter plots (Figures 2-10). In addition, values for the relationships between the variables are given in Table 4 . 


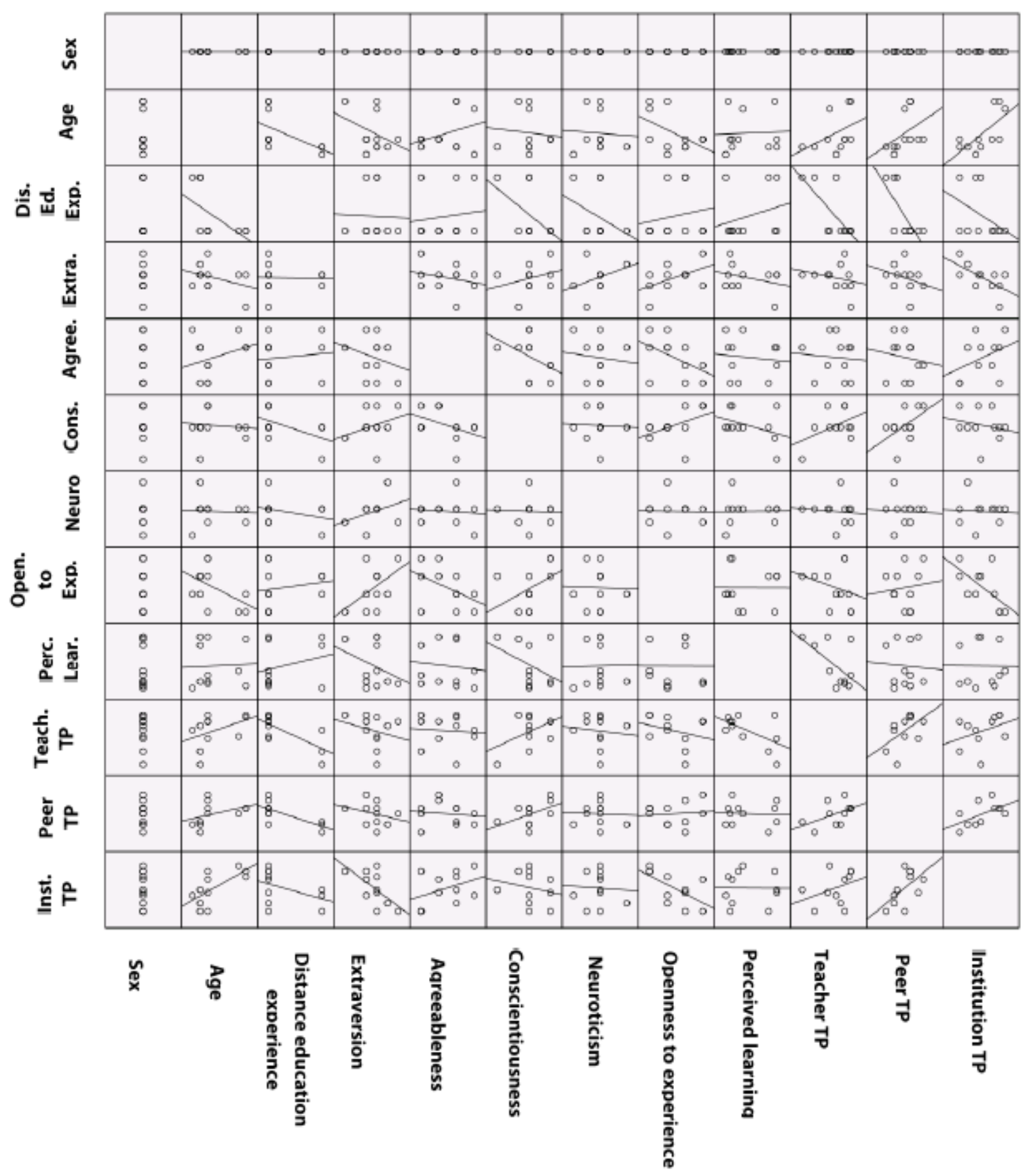

Figure 1. Multiple scatter plot for the variables in the regression model 


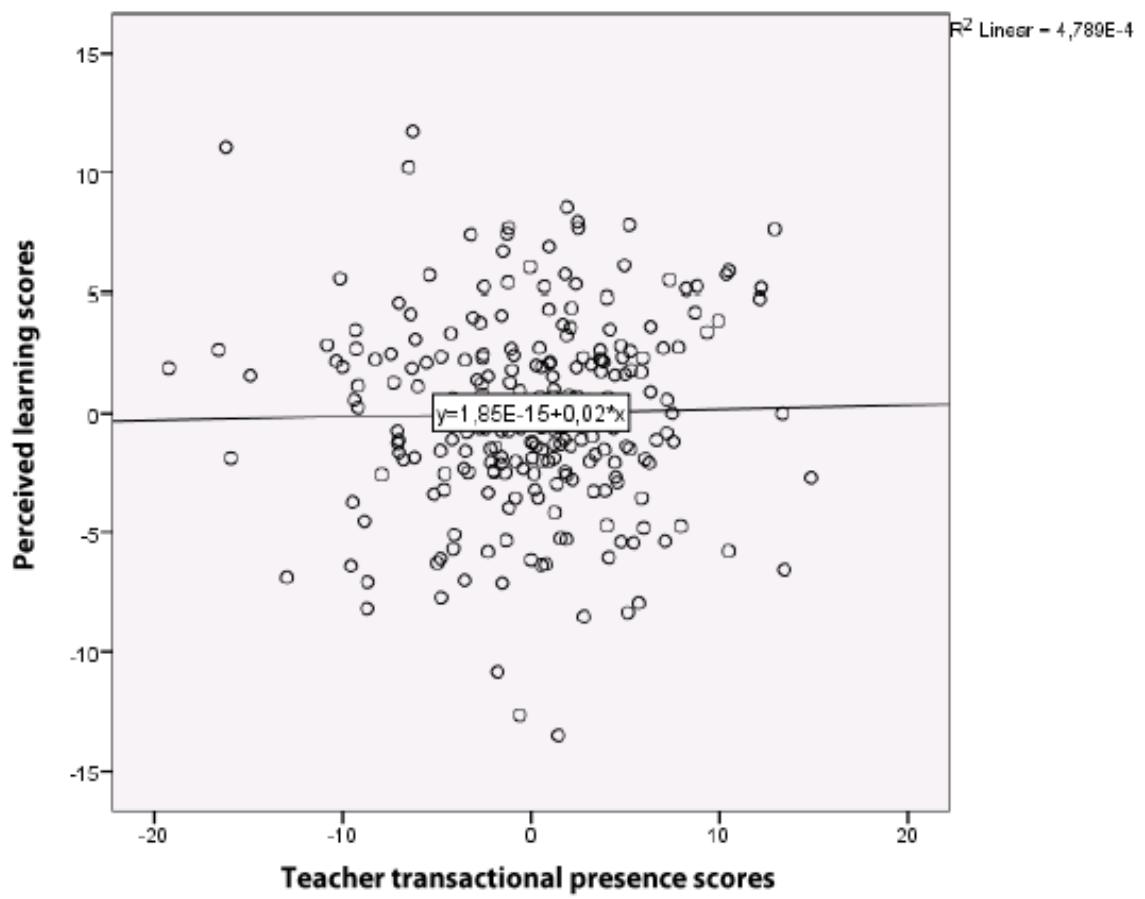

Figure 2. Scatter plot of the relationship between perceived learning and teacher transactional presence

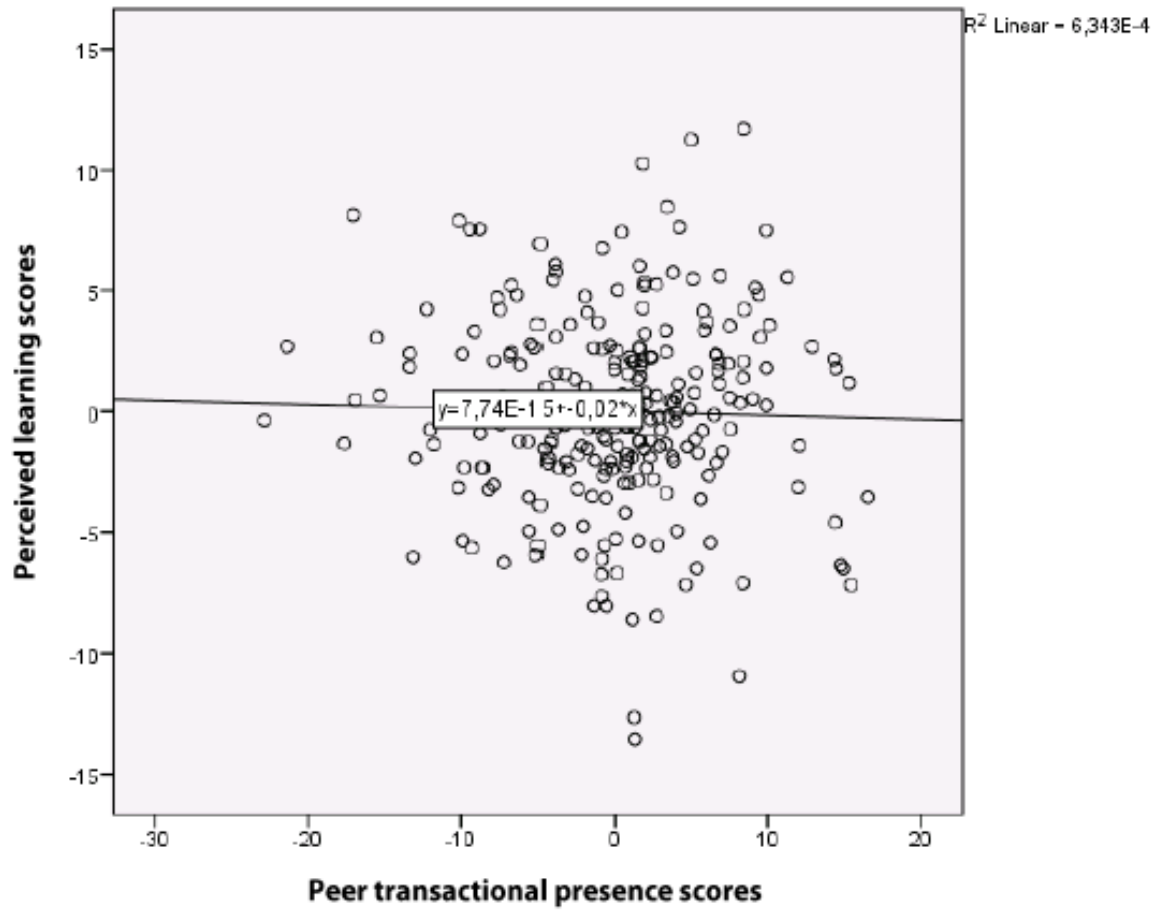

Figure 3. Scatter plot of the relationship between perceived learning and peer transactional presence 


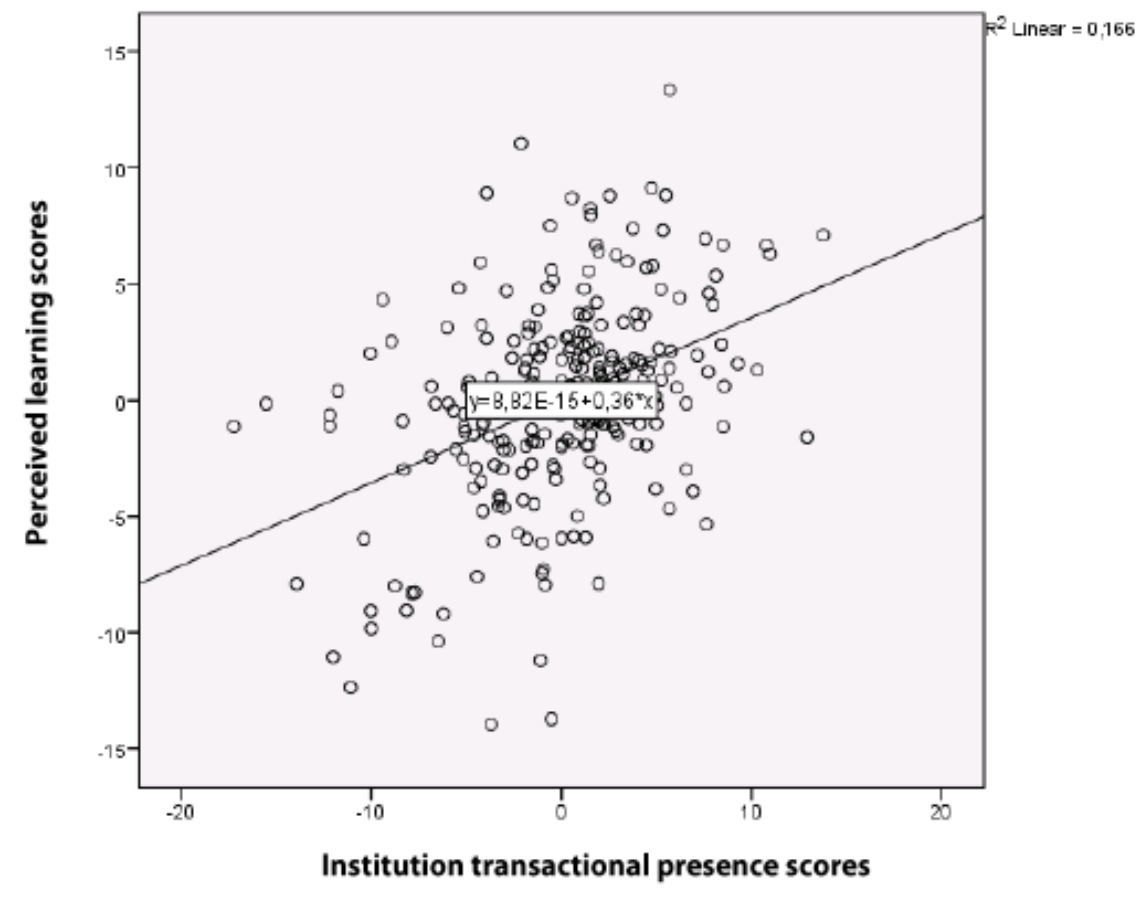

Figure 4. Scatter plot of the relationship between perceived learning and institution transactional presence

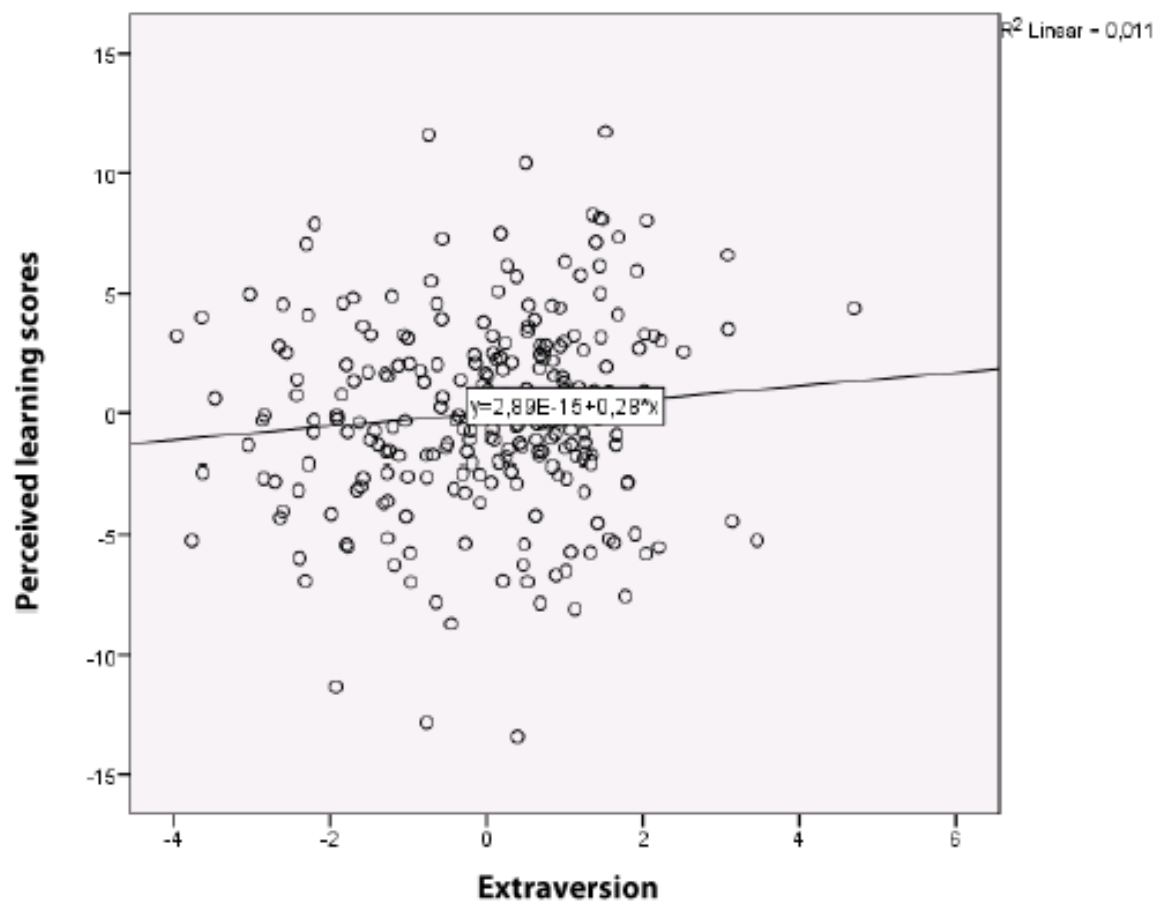

Figure 5. Scatter plot of the relationship between perceived learning and extraversion 


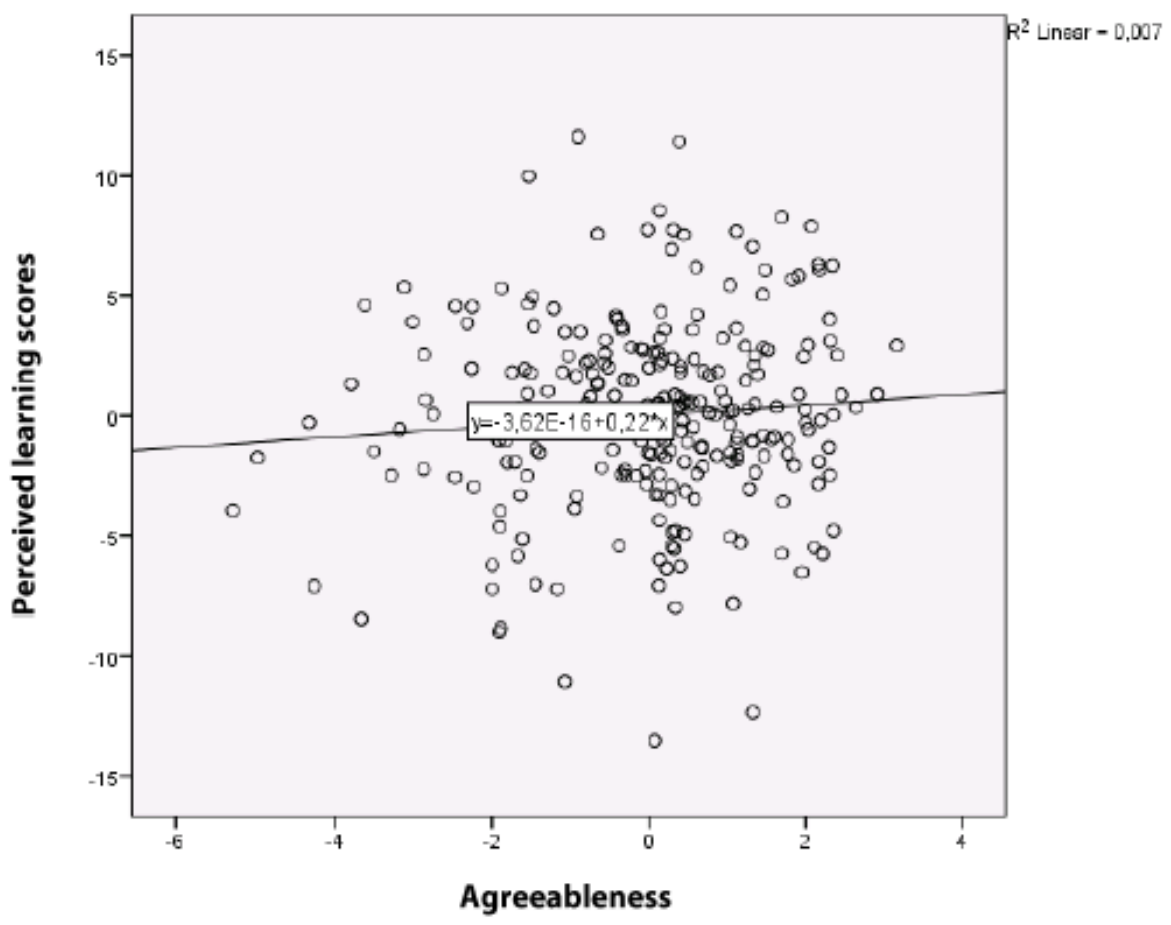

Figure 6. Scatter plot of the relationship between perceived learning and agreeableness

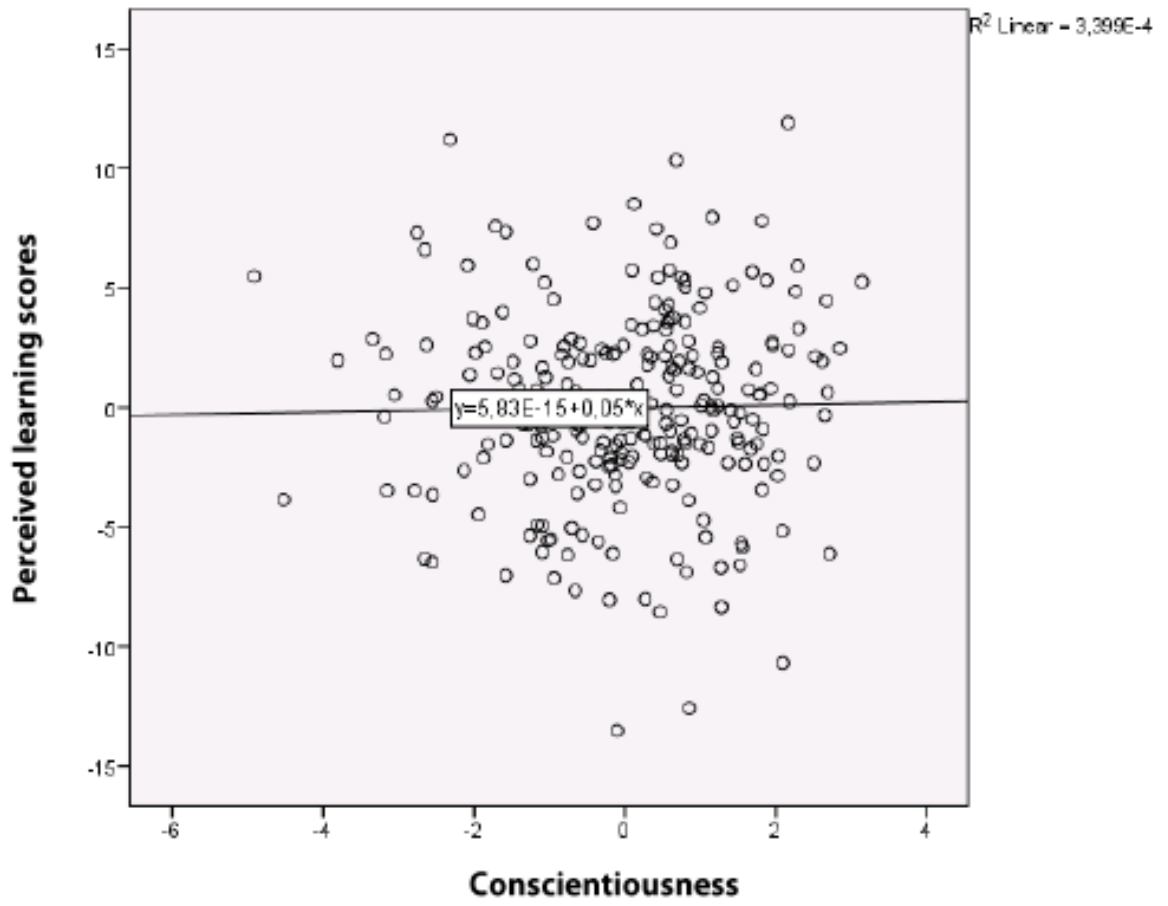

Figure 7. Scatter plot of the relationship between perceived learning and conscientiousness 


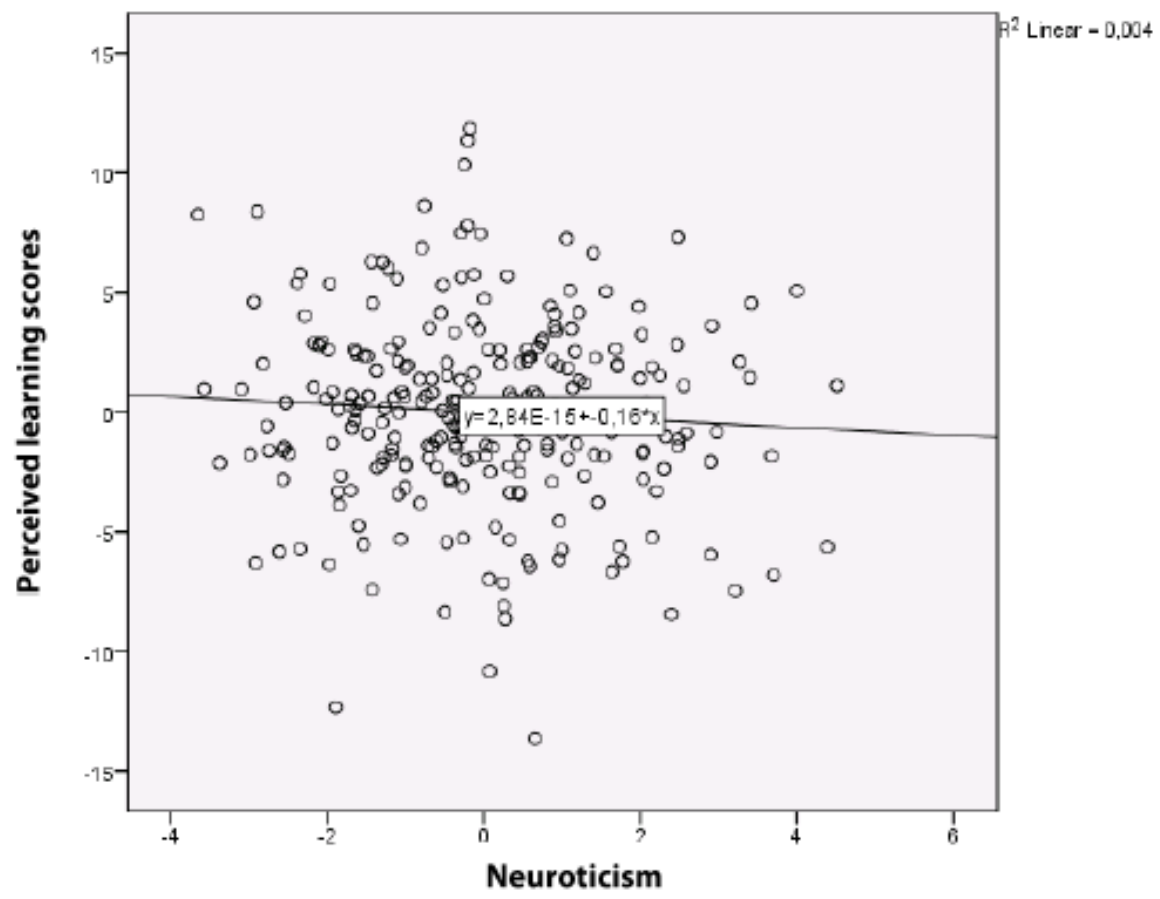

Figure 8. Scatter plot of the relationship between perceived learning and neuroticism

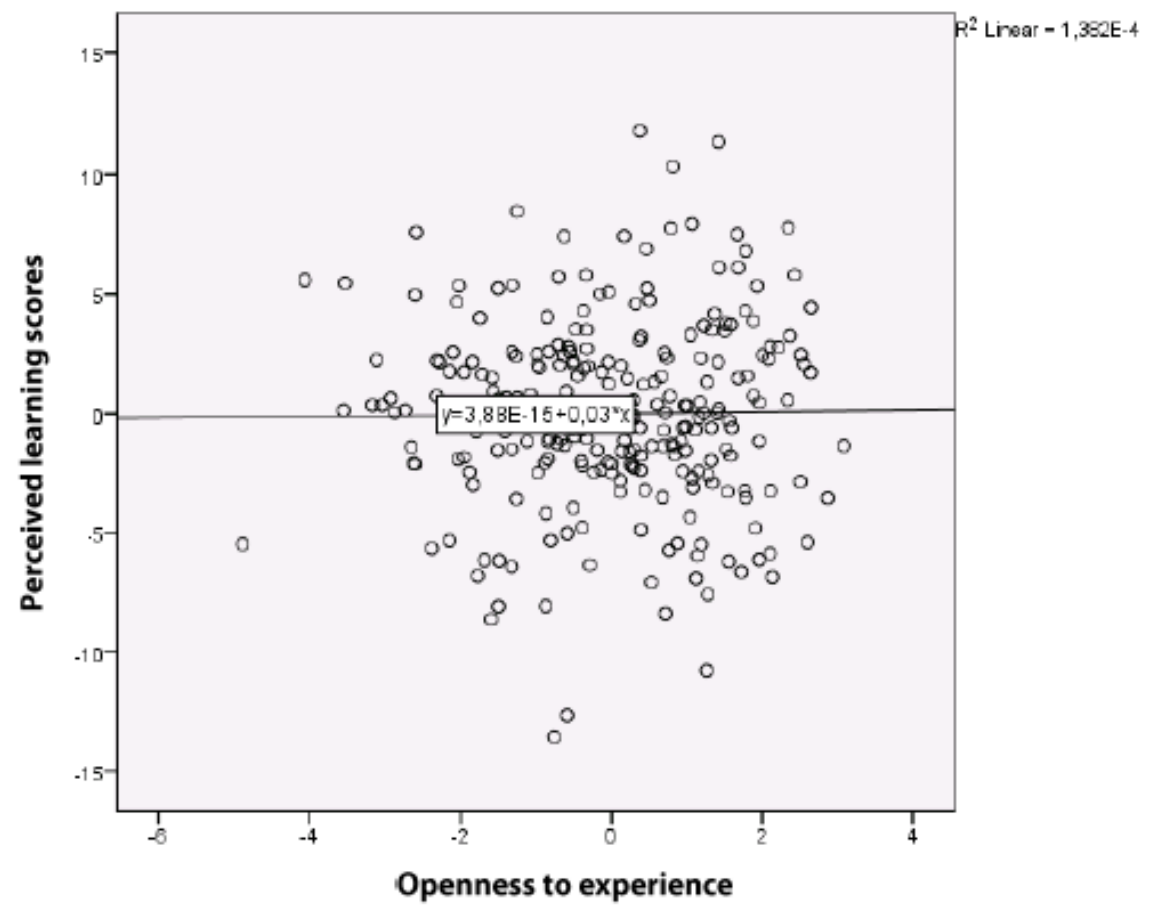

Figure 9. Scatter plot of the relationship between perceived learning and openness to experience 


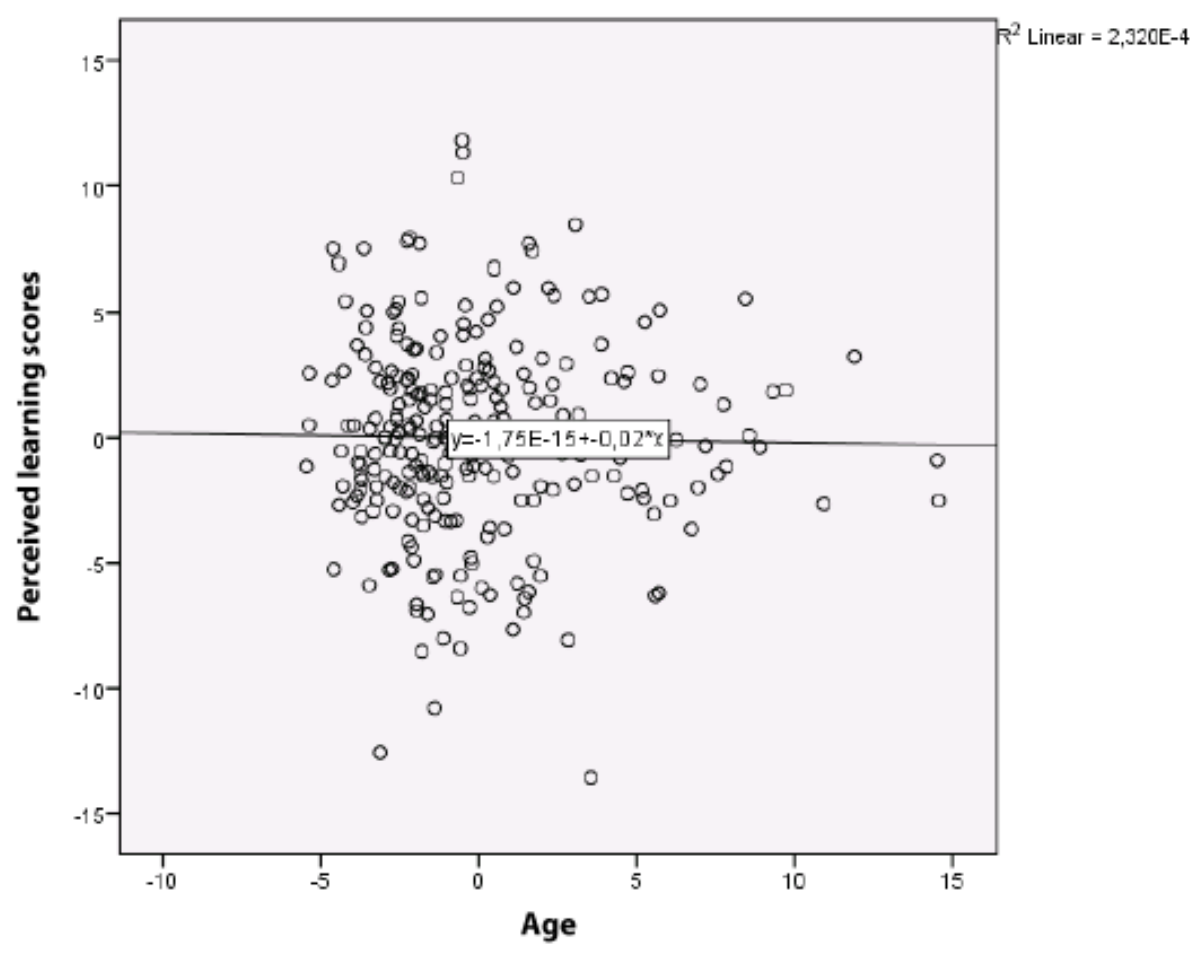

Figure 10. Scatter plot of the relationship between perceived learning and age

Table 4. Pearson's correlation test showing the relationships between the variables in the regression model

\begin{tabular}{|c|c|c|c|c|c|c|c|c|c|c|c|c|}
\hline$n=260$ & 1 & 2 & 3 & 4 & 5 & 6 & 7 & 8 & 9 & 10 & 11 & 12 \\
\hline 1. Perceived learning & 1.000 & $0.368^{* *}$ & $0.269^{* *}$ & $0.536^{* *}$ & $0.216^{* *}$ & $0.156^{* *}$ & $0.201^{* *}$ & $-0.170^{* *}$ & $0.121^{*}$ & 0.095 & 0.102 & 0.050 \\
\hline 2. Teacher TP & & 1.000 & $0.438^{* *}$ & $0.625^{* *}$ & $0.237^{* *}$ & 0.094 & $0.270^{* *}$ & $-0.263^{* *}$ & $0.232^{* *}$ & -0.059 & $0.241^{* *}$ & 0.089 \\
\hline 3. Peer TP & & & 1.000 & $0.468^{* *}$ & $0.327^{* *}$ & 0.085 & $0.270^{* *}$ & $-0.121^{*}$ & 0.101 & 0.022 & $0.122^{*}$ & -0.025 \\
\hline 4. Institution TP & & & & 1.000 & $0.177^{* *}$ & $0.117^{*}$ & $0.216^{* *}$ & $-0.186^{* *}$ & $0.137^{*}$ & -0.021 & 0.225 & 0.069 \\
\hline 5. Extraversion & & & & & 1.000 & 0.078 & 0.451 & -0.196 & 0.253 & 0.023 & 0.050 & -0.012 \\
\hline 6. Agreeableness & & & & & & 1.000 & 0.102 & -0.052 & 0.086 & $0.128^{*}$ & 0.005 & -0.045 \\
\hline 7. Conscientiousness & & & & & & & 1.000 & -0.065 & $0.245^{* *}$ & $0.190^{* *}$ & 0.064 & -0.035 \\
\hline 8. Neuroticism & & & & & & & & 1.000 & $-0.110^{*}$ & 0.086 & $-0.140^{*}$ & -0.061 \\
\hline $\begin{array}{l}\text { 9. Openness to } \\
\text { experience }\end{array}$ & & & & & & & & & 1.000 & -0.019 & 0.036 & -0.015 \\
\hline 10. Sex & & & & & & & & & & 1.000 & $-0.153^{* *}$ & -0.070 \\
\hline 11. Age & & & & & & & & & & & 1.000 & 0.061 \\
\hline $\begin{array}{l}\text { 12. Distance } \\
\text { education } \\
\text { experience }\end{array}$ & & & & & & & & & & & & 1.000 \\
\hline
\end{tabular}

Also, homoscedasticitiy, normal distribution (randomness) of errors, and perfect multicollinearity between the variables were tested. Findings regarding the relevant tests are shown in Figure 11-12-13 and Table 5. 


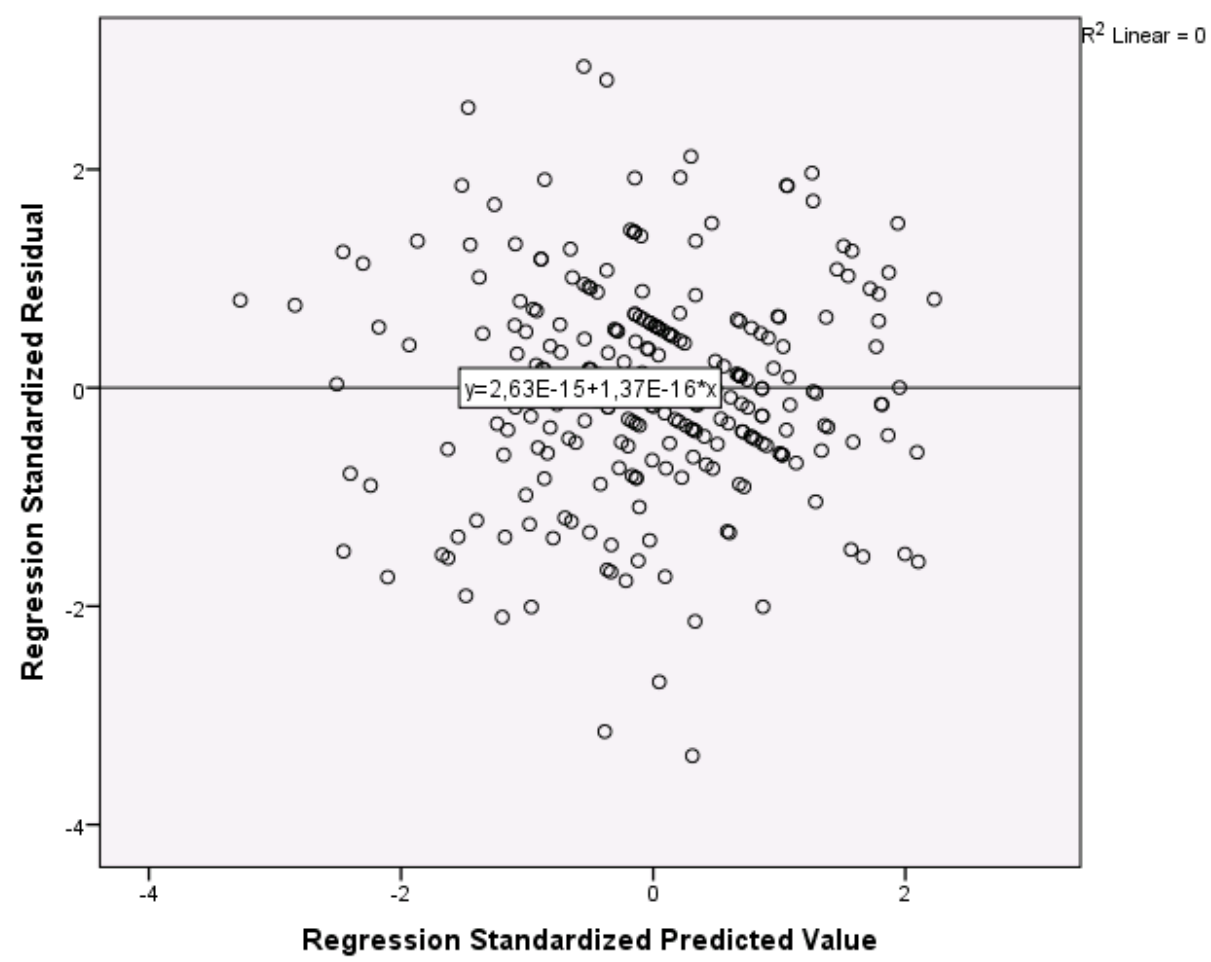

Figure 11. Scatter plot of standardized residual

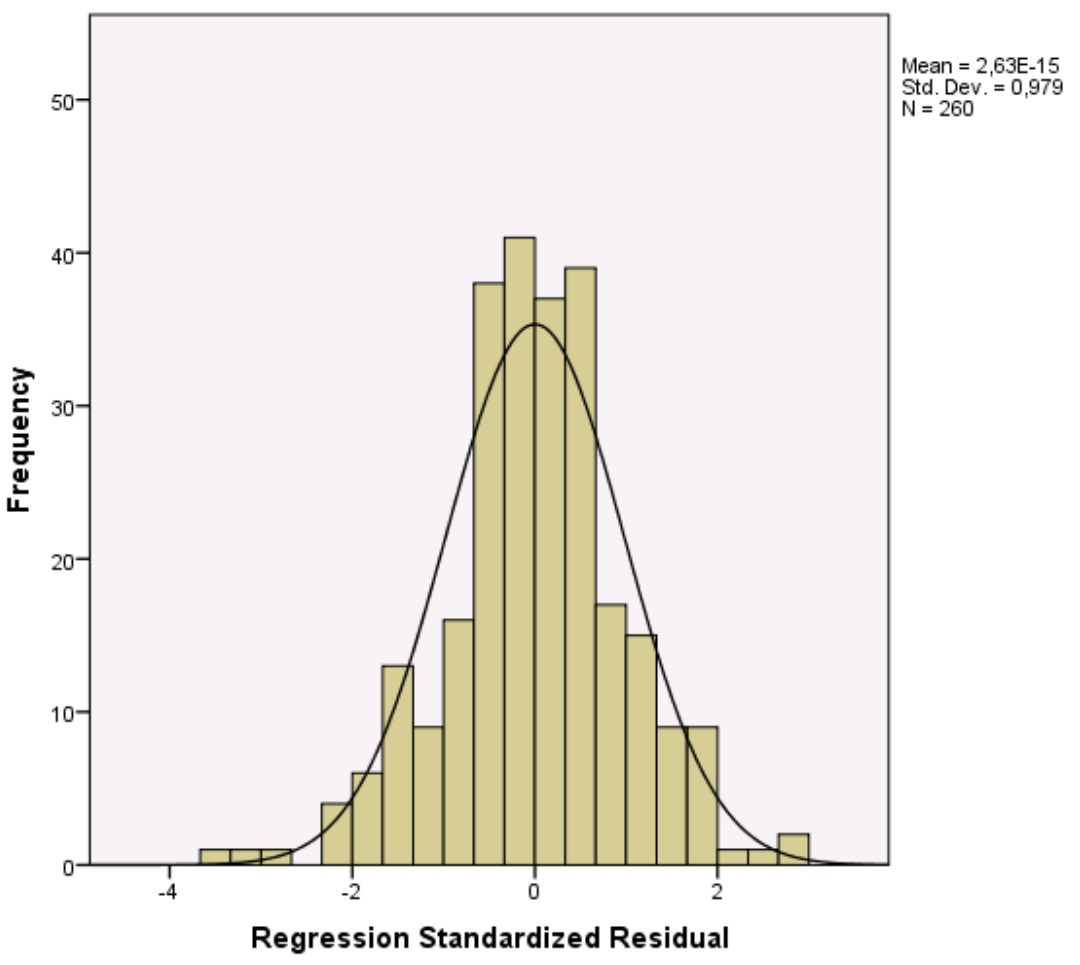

Figure 12. Histogram of standardized residual 


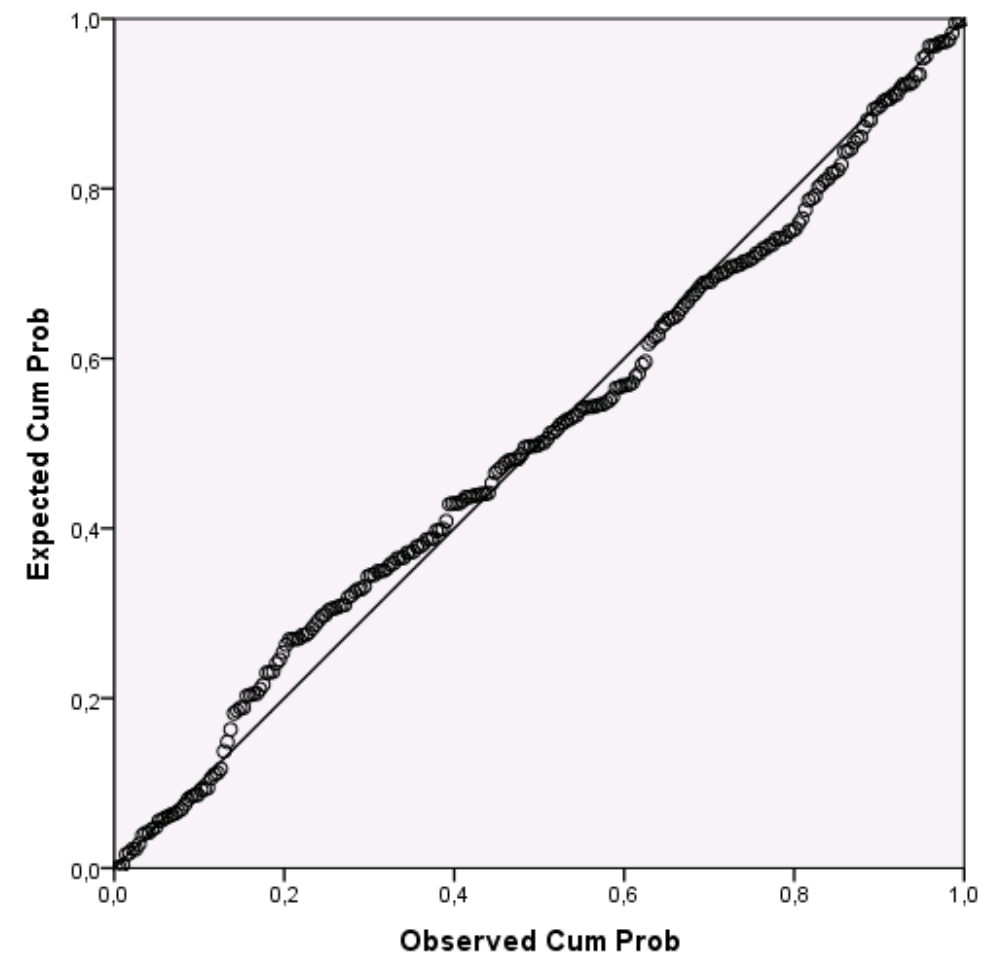

Figure 13. P-P graph of standardized residual

Table 5. Parameters for the regression model

\begin{tabular}{|c|c|c|c|c|c|c|c|c|c|c|c|c|c|}
\hline \multirow{2}{*}{\multicolumn{2}{|c|}{ Model }} & \multicolumn{2}{|c|}{$\begin{array}{l}\text { Non-standardized } \\
\text { coefficients }\end{array}$} & \multirow{2}{*}{$\begin{array}{l}\text { Standardized } \\
\text { coefficients }\end{array}$} & \multirow[b]{2}{*}{$\mathrm{t}$} & \multirow[b]{2}{*}{$p$} & \multicolumn{2}{|c|}{$\begin{array}{l}95 \% \text { confidence } \\
\text { interval for B }\end{array}$} & \multicolumn{3}{|c|}{ Correlations } & \multicolumn{2}{|c|}{$\begin{array}{l}\text { Collinearity } \\
\text { statistics }\end{array}$} \\
\hline & & B & $\begin{array}{l}\text { Standard } \\
\text { Error }\end{array}$ & & & & $\begin{array}{l}\text { Lower } \\
\text { limit }\end{array}$ & $\begin{array}{l}\text { Upper } \\
\text { limit }\end{array}$ & $\begin{array}{l}\text { Zero } \\
\text { order }\end{array}$ & Partial & Segmented & Tolerance & VIF \\
\hline \multirow[t]{12}{*}{1} & Constant & 16.210 & 3.067 & & 5.285 & 0.000 & 10.169 & 22.251 & & & & & \\
\hline & Teacher TP & 0.016 & 0.045 & 0.025 & 0.345 & 0.731 & -0.074 & 0.105 & 0.368 & 0.022 & 0.018 & 0.527 & 1.897 \\
\hline & Peer TP & -0.015 & 0.038 & -0.025 & -0.397 & 0.692 & -0.090 & 0.059 & 0.269 & -0.025 & -0.021 & 0.687 & 1.455 \\
\hline & Institution TP & 0.356 & 0.051 & 0.493 & 7.014 & 0.000 & 0.256 & 0.456 & 0.536 & 0.407 & 0.366 & 0.552 & 1.810 \\
\hline & Extraversion & 0.280 & 0.171 & 0.102 & 1.642 & 0.102 & -0.056 & 0.616 & 0.216 & 0.104 & 0.086 & 0.710 & 1.408 \\
\hline & Agreeableness & 0.222 & 0.163 & 0.073 & 1.363 & 0.174 & -0.099 & 0.542 & 0.156 & 0.086 & 0.071 & 0.959 & 1.043 \\
\hline & Conscientiousness & 0.050 & 0.173 & 0.018 & 0.290 & 0.772 & -0.291 & 0.392 & 0.201 & 0.018 & 0.015 & 0.710 & 1.409 \\
\hline & Neuroticism & -0.162 & 0.155 & -0.058 & -1.050 & 0.295 & -0.467 & 0.142 & -0.170 & -0.067 & -0.055 & 0.894 & 1.118 \\
\hline & $\begin{array}{l}\text { Openness to } \\
\text { experience }\end{array}$ & 0.031 & 0.170 & 0.010 & 0.185 & 0.853 & -0.303 & 0.366 & 0.121 & 0.012 & 0.010 & 0.881 & 1.135 \\
\hline & Sex & 0.993 & 0.561 & 0.097 & 1.769 & 0.078 & -0.112 & 2.098 & 0.095 & 0.112 & 0.092 & 0.906 & 1.104 \\
\hline & Age & -0.017 & 0.071 & -0.013 & -0.240 & 0.811 & -0.157 & 0.123 & 0.102 & -0.015 & -0.013 & 0.906 & 1.104 \\
\hline & $\begin{array}{l}\text { Distance } \\
\text { education } \\
\text { experience }\end{array}$ & 0.218 & 0.513 & 0.022 & 0.425 & 0.671 & -0.792 & 1.229 & 0.050 & 0.027 & 0.022 & 0.976 & 1.025 \\
\hline
\end{tabular}

Finally, a multiple linear regression analysis was performed based on testing and verifying the assumptions. 


\section{RESULTS}

In the presentation of the results, mainly the results from the scale adaptation procedure were presented. This part of the study includes the results of EFA performed to determine the structure of the scale in Turkish students and the results of CFA performed to determine whether the scale structure was confirmed in the research sample. This part also presents the reliability test results and the results of the Pearson's correlation analysis performed between TIPI scores and TP perceptions in order to examine the relationship between TP perceptions and personality traits, an important variable in the field of distance education (Busari, 2017; Randler, Horzum \& Vollmer, 2014; Siddiquei \& Khalid, 2018; Bhagat, Wu \& Chang, 2019; Bayram, Deniz \& Erdogan, 2008; Bahcekapılı \& Karaman, 2015) as they were taken as criteria for TP. This part finally presents the results of the multiple linear regression analysis performed on the data obtained using the Turkish version of the TP scale.

\section{EFA Results}

The TP scale consists of three main dimensions: teacher TP, peer TP and institution TP. In other words, the 37-item TP scale consists of three scales: teacher, peer and institution TP scales. For this reason, EFA was conducted for each dimension, and the results were presented below.

\section{EFA Results for the Teacher TP Scale}

EFA was performed on the 13 items in the teacher TP scale. Kaiser-Meyer-Olkin (KMO) test was used for sample adequacy and Bartlett's Sphericity value was used to examine the fitness of the data for factor analysis. $\mathrm{KMO}$ value was found to be 0.898 in the analysis. Since this value was between 0.8 and 0.9 , the sample was found to be adequate (at a good level) for factor analysis (Kaiser, 1974). Bartlett's Sphericity test showed that the relationship between the variables was significantly different from 0 . and it was concluded that EFA could be performed with the data $\left(X^{2}=2248.773 ; \mathrm{p}<0.001\right)$. In the factor analysis, varimax axis rotation was performed on 13 items and a principal components factor analysis was performed with an eigenvalue of 1. These steps were preferred in factor analysis because it was expected that there would be no relationship between the factors of the scale and varimax rotation had also been performed in the original scale (Shin, 2001). The analysis results showed that the scale consisted of three factors. It was also observed that the eigenvalue-factor number graph confirmed the three-factor structure. Table 6 shows the results of EFA.

Table 6. Principal components and varimax rotation EFA results for the teacher TP scale

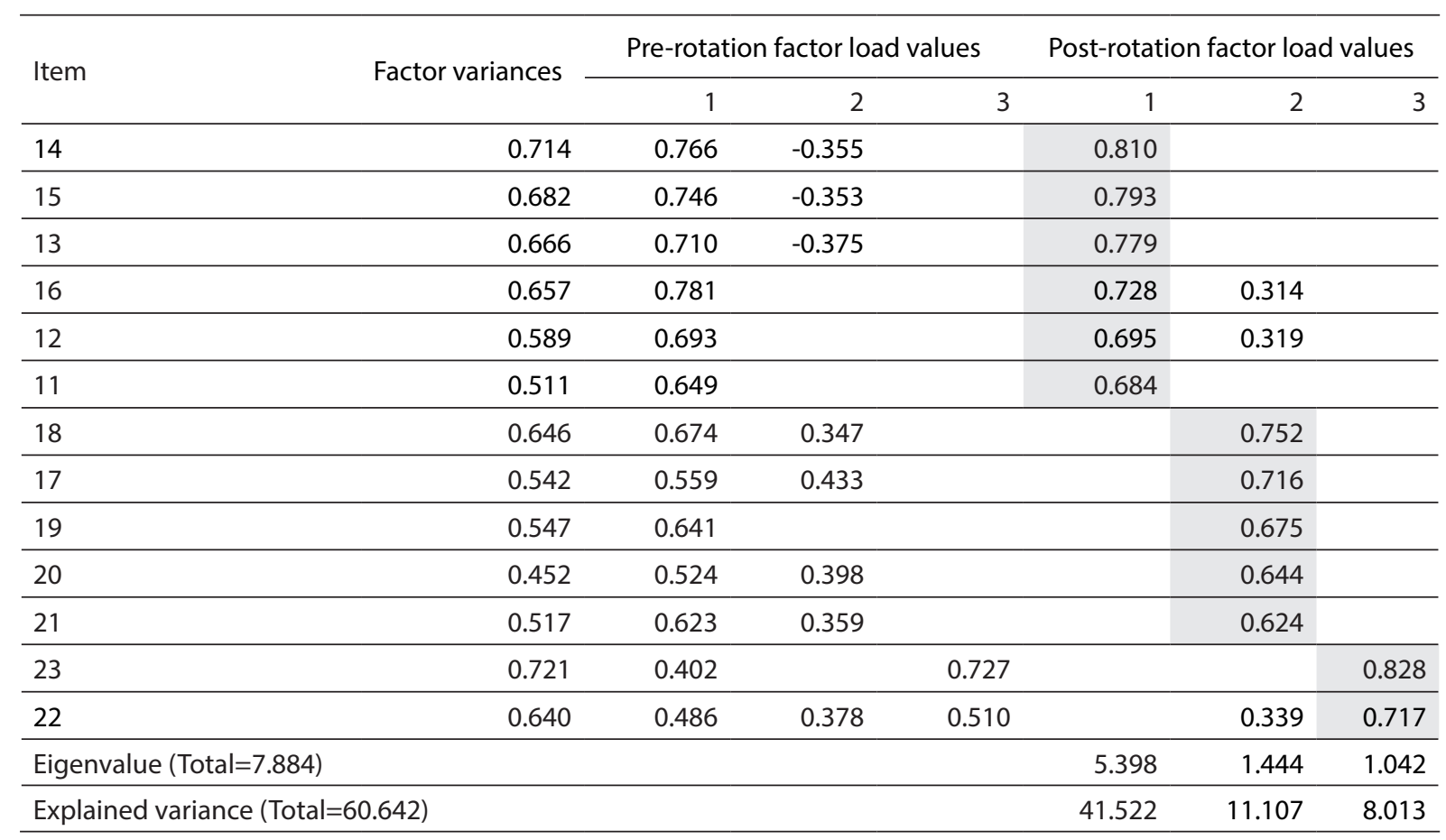




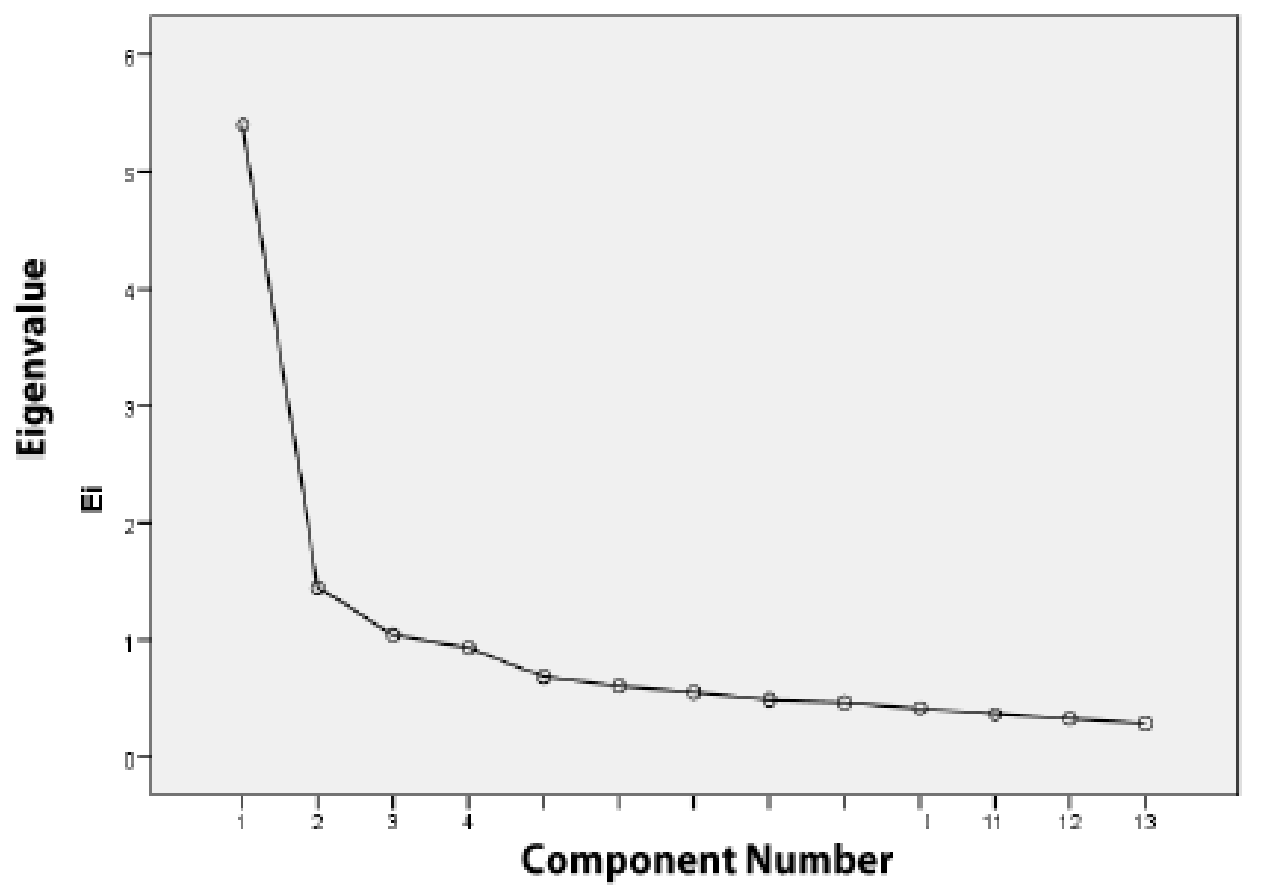

Figure 14. Teacher TP EFA scree plot

The analysis results showed that the eigenvalue of the first factor of the three-factor scale was 5.398 and the variance explained was $41.522 \%$. The eigenvalue of the second factor was 1.444 and the variance explained was $11.107 \%$. The eigenvalue of the third factor was 1.042 and the variance explained was $8.013 \%$. The total eigenvalue of the scale was 7.884 and the total variance explained was $60.642 \%$. This result suggests that the variance explained by the scale adequately explained the quality that was measured. In addition, the factor structure of the original scale exhibited a similar structure among Turkish students. In the original scale, the first factor represented teacher availability, which made up the sub-dimensions of teacher TP, while the second and third factors represented teacher connectedness. All the items in the Turkish version of the TP scale were found to be compatible with the sub-factors of the original scale and were included in the same factor groups within the same cluster. As a result, the 13 items and three sub-factor structure in the Turkish version of the teacher TP scale had similar properties to the original form.

\section{EFA Results for the Peer TP Scale}

EFA was performed on the 13 items in the peer TP scale. KMO test was used for sample adequacy and Bartlett's Sphericity value was used to examine the fitness of the data for factor analysis. KMO value was found to be 0.928 in the analysis. Since this value was between 0.8 and 0.9 , the sample was found to be adequate (at a good level) for factor analysis (Kaiser, 1974). Bartlett's Sphericity test showed that the relationship between the variables was significantly different from 0 . and it was concluded that EFA could be performed with the data $\left(\mathrm{X}^{2}=3473.349 ; \mathrm{p}<0.001\right)$. In the factor analysis, varimax axis rotation was performed on 13 items and a principal components factor analysis was performed with an eigenvalue of 1. These steps were preferred in factor analysis because it was expected that there would be no relationship between the factors of the scale and varimax rotation had also been performed in the original scale (Shin, 2001). As a result of the analysis, it was found that some items had load values on more than one factor after varimax rotation. Table 7 shows the first EFA results. Buyukozturk (2011, p. 125) recommended that the difference between the two high load values should be at least 0.10 when eliminating the items that do not measure the same structure in factor analysis. Therefore, Item 24 was excluded from analysis as it did 
not meet the specified criterion and EFA was performed again on the remaining items. The analysis results showed that the scale consisted of two factors. It was also observed that the eigenvalue-factor number graph reflected and confirmed the two-factor structure. Table 8 and Figure 16 show the second EFA results and the eigenvalue-factor number graph.

Table 7. Principal components and varimax rotation EFA results for the peer TP scale-1

\begin{tabular}{|c|c|c|c|c|c|}
\hline \multirow{2}{*}{ Item } & \multirow{2}{*}{ Factor variances } & \multicolumn{2}{|c|}{ Pre-rotation factor load values } & \multicolumn{2}{|c|}{ Post-rotation factor load values } \\
\hline & & 1 & 2 & 1 & 2 \\
\hline 35 & 0.730 & 0.813 & & 0.762 & 0.387 \\
\hline 27 & 0.729 & 0.807 & & 0.378 & 0.766 \\
\hline 26 & 0.795 & 0.786 & -0.420 & & 0.852 \\
\hline 30 & 0.610 & 0.773 & & 0.469 & 0.625 \\
\hline 34 & 0.729 & 0.762 & 0.386 & 0.813 & \\
\hline 25 & 0.760 & 0.752 & -0.441 & & 0.843 \\
\hline 32 & 0.655 & 0.736 & 0.337 & 0.759 & \\
\hline 36 & 0.620 & 0.730 & & 0.726 & 0.305 \\
\hline 29 & 0.600 & 0.708 & -0.313 & & 0.721 \\
\hline 33 & 0.706 & 0.689 & 0.480 & 0.828 & \\
\hline 31 & 0.482 & 0.679 & & 0.583 & 0.377 \\
\hline 28 & 0.539 & 0.652 & -0.338 & & 0.699 \\
\hline 24 & 0.274 & 0.522 & & 0.395 & 0.343 \\
\hline \multicolumn{2}{|c|}{ Eigenvalue $($ Total=8.228) } & & & 6.885 & 1.343 \\
\hline \multicolumn{2}{|c|}{ Explained variance $($ Total $=63.287$ ) } & & & 52.959 & 10.328 \\
\hline
\end{tabular}

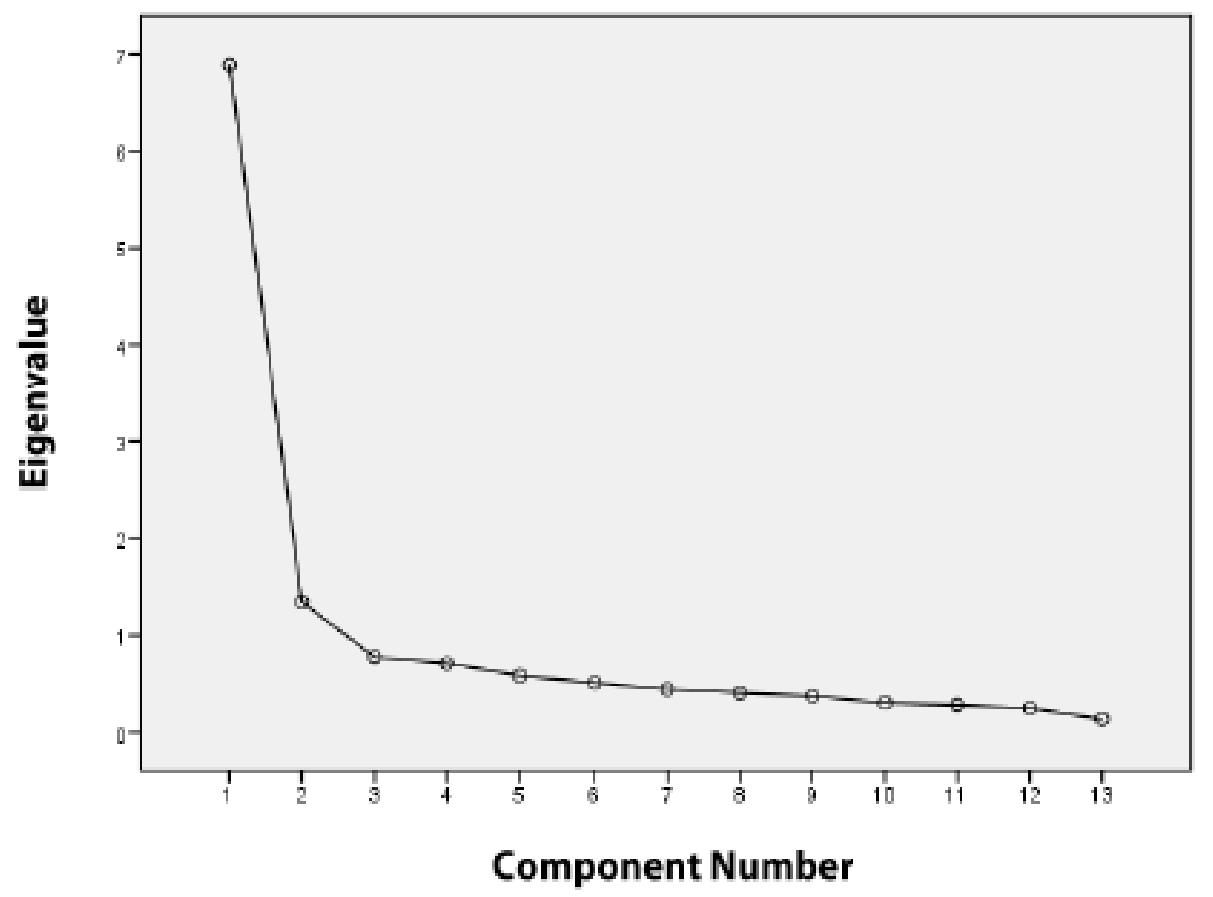

Figure 15. Peer TP first EFA scree plot 
Table 8. Principal components and varimax rotation EFA results for the peer TP scale-2

\begin{tabular}{|c|c|c|c|c|c|}
\hline \multirow[t]{2}{*}{ Item } & \multirow[t]{2}{*}{ Factor variances } & \multicolumn{2}{|c|}{ Pre-rotation factor load values } & \multicolumn{2}{|c|}{$\begin{array}{l}\text { Post-rotation factor load } \\
\text { values }\end{array}$} \\
\hline & & 1 & 2 & 1 & 2 \\
\hline 35 & 0.729 & 0.811 & & 0.388 & 0.760 \\
\hline 27 & 0.732 & 0.809 & & 0.771 & 0.372 \\
\hline 26 & 0.797 & 0.790 & -0.417 & 0.854 & \\
\hline 30 & 0.613 & 0.775 & & 0.629 & 0.467 \\
\hline 34 & 0.732 & 0.761 & 0.391 & & 0.813 \\
\hline 25 & 0.763 & 0.756 & -0.437 & 0.844 & \\
\hline 32 & 0.655 & 0.735 & 0.339 & & 0.758 \\
\hline 36 & 0.626 & 0.732 & 0.300 & 0.308 & 0.729 \\
\hline 29 & 0.595 & 0.707 & -0.307 & 0.718 & \\
\hline 33 & 0.716 & 0.692 & 0.487 & & 0.833 \\
\hline 31 & 0.474 & 0.674 & & 0.382 & 0.573 \\
\hline 28 & 0.543 & 0.653 & -0.341 & 0.704 & \\
\hline \multicolumn{2}{|c|}{ Eigenvalue (Total=7.974) } & & & 6.624 & 1.350 \\
\hline \multicolumn{2}{|c|}{ Explained variance $($ Total $=66.45)$} & & & 55.203 & 11.247 \\
\hline
\end{tabular}

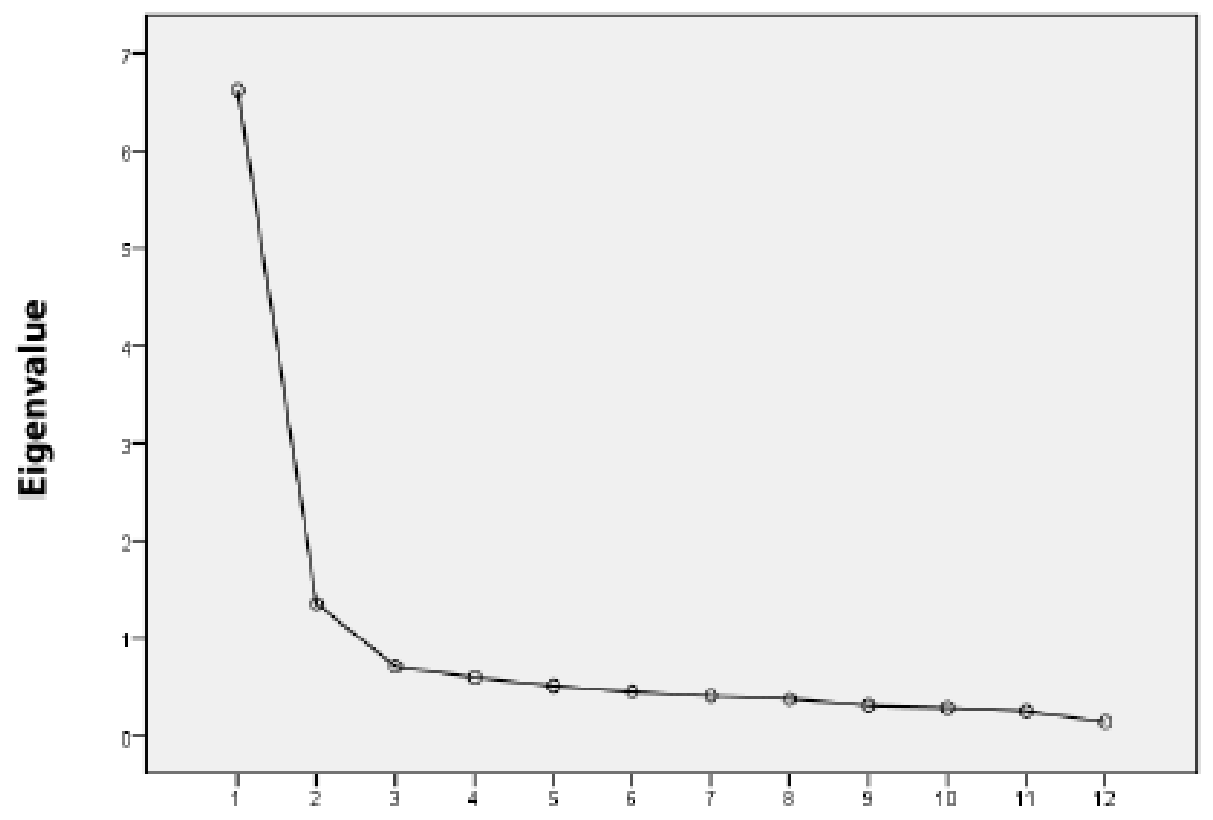

Component Number

Figure 16. Peer TP second EFA scree plot

The analysis results showed that the eigenvalue of the first factor of the two-factor scale was 6.624 and the variance explained was $55.203 \%$ and the eigenvalue of the second factor was 1.350 and the variance explained was $11.247 \%$. The total eigenvalue of the scale was 7.974 and the total variance explained was $66.45 \%$. This result suggests that the variance explained by the scale adequately explained the quality that was measured. Also, the factor structure of the original scale exhibited a similar structure among Turkish 
students. All items except three items in the Turkish form (Items 24, 30 and 31) were found to make up the same factors within the same cluster as in the original scale. The first factor represented peer connectedness, which made up the sub-dimensions of peer TP, while the second factor represented peer availability. As a result, the factor structure of the original scale exhibited a similar structure among Turkish students and the 13 items and two sub-factor structure in the Turkish version of the peer TP scale had similar properties to the original scale.

\section{EFA Results for the Institution TP Scale}

EFA was performed on the 11 items in the institution TP scale. KMO test was used for sample adequacy and Bartlett's Sphericity value was used to examine the fitness of the data for factor analysis. KMO value was found to be 0.820 in the analysis. Since this value was between 0.8 and 0.9 , the sample was found to be adequate (at a good level) for factor analysis (Kaiser, 1974). Bartlett's Sphericity test showed that the relationship between the variables was significantly different from 0 . and it was concluded that EFA could be performed with the data $\left(X^{2}=1842.435 ; \mathrm{p}<0.001\right)$. In the factor analysis, varimax axis rotation was performed on 11 items and a principal components factor analysis was performed with an eigenvalue of 1. These steps were preferred in factor analysis because it was expected that there would be no relationship between the factors of the scale and varimax rotation had also been performed in the original scale (Shin, 2001). As a result of the analysis, it was found that some items had load values on more than one factor after varimax rotation. Table 9 shows the first EFA results. Buyukozturk (2011, p. 125) recommended that the difference between the two high load values should be at least 0.10 when eliminating the items that do not measure the same structure in factor analysis. Therefore, Item 40 was excluded from analysis because it did not meet the specified criterion and EFA was performed again on the remaining items. The analysis results showed that the scale consisted of three factors. It was also observed that the eigenvalue-factor number graph reflected and confirmed the three-factor structure. Table 10 and Figure 18 show the second EFA results and the eigenvalue-factor number graph.

Table 9. Principal components and varimax rotation EFA results for the institution TP scale-1

\begin{tabular}{|c|c|c|c|c|c|c|c|}
\hline \multirow{2}{*}{ Item } & \multirow{2}{*}{$\begin{array}{l}\text { Factor } \\
\text { variances }\end{array}$} & \multicolumn{3}{|c|}{ Pre-rotation factor load values } & \multicolumn{3}{|c|}{ Post-rotation factor load values } \\
\hline & & 1 & 2 & 3 & 1 & 2 & 3 \\
\hline 41 & 0.769 & 0.794 & & -0.364 & 0.853 & & \\
\hline 42 & 0.736 & 0.799 & & & 0.823 & & \\
\hline 44 & 0.564 & 0.714 & & & 0.699 & & \\
\hline 45 & 0.478 & 0.651 & & & 0.645 & & \\
\hline 43 & 0.466 & 0.620 & & & 0.623 & & \\
\hline 40 & 0.468 & 0.614 & & & 0.509 & 0.451 & \\
\hline 37 & 0.727 & 0.627 & -0.465 & 0.344 & & 0.819 & \\
\hline 38 & 0.719 & 0.614 & -0.546 & & & 0.810 & \\
\hline 39 & 0.505 & 0.471 & -0.421 & 0.326 & & 0.698 & \\
\hline $46 \_r$ & 0.757 & 0.436 & 0.553 & 0.512 & & & 0.853 \\
\hline 47_r & 0.714 & 0.489 & 0.517 & 0.455 & & & 0.809 \\
\hline Eigenvalue (Total=6.905) & & & & & 4.387 & 1.457 & 1.061 \\
\hline Explained variance (Total= & (771) & & & & 39.882 & 13.244 & 9.645 \\
\hline
\end{tabular}




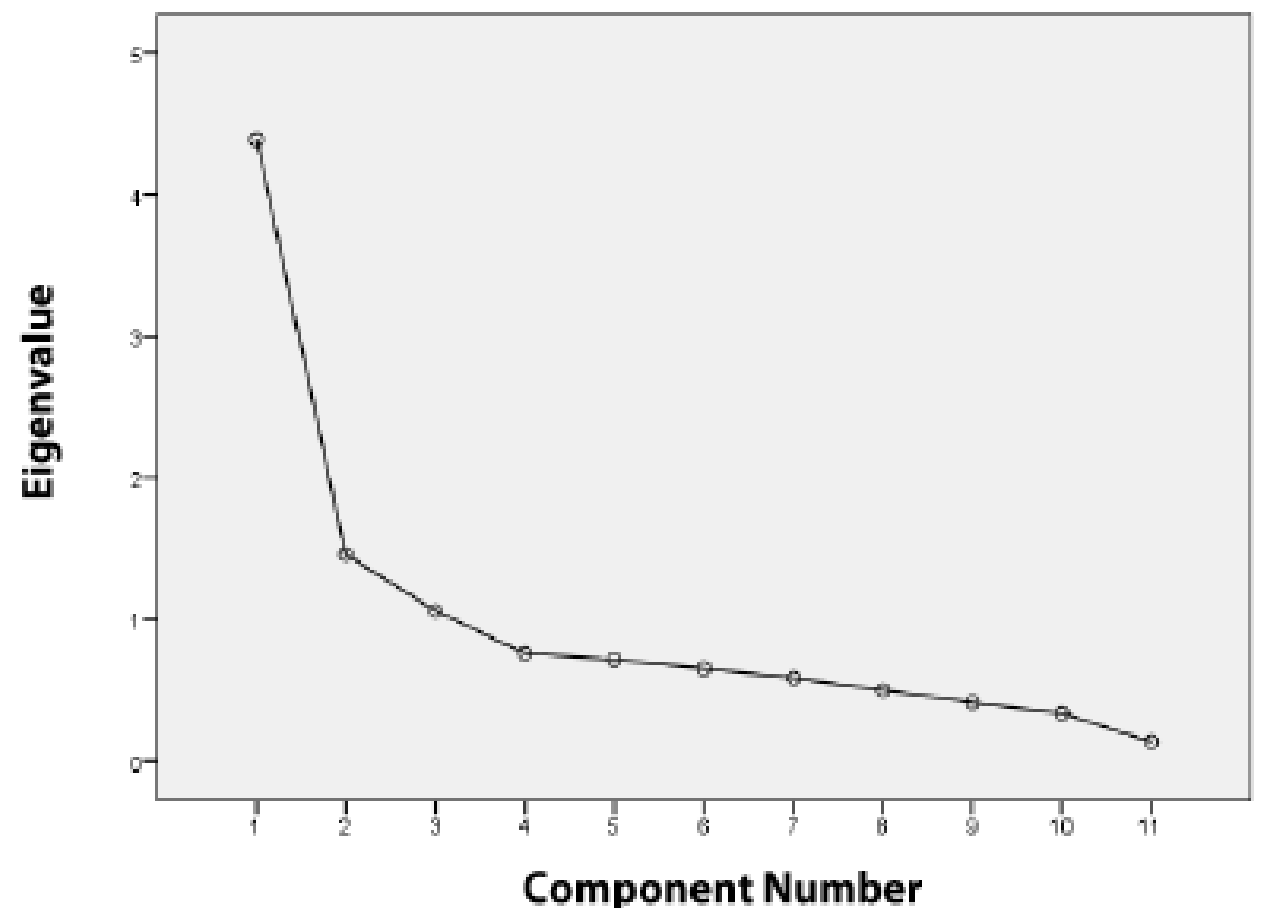

Figure 17. Institution TP first EFA scree plot

Table 10. Principal components and varimax rotation EFA results for the institution TP scale-2

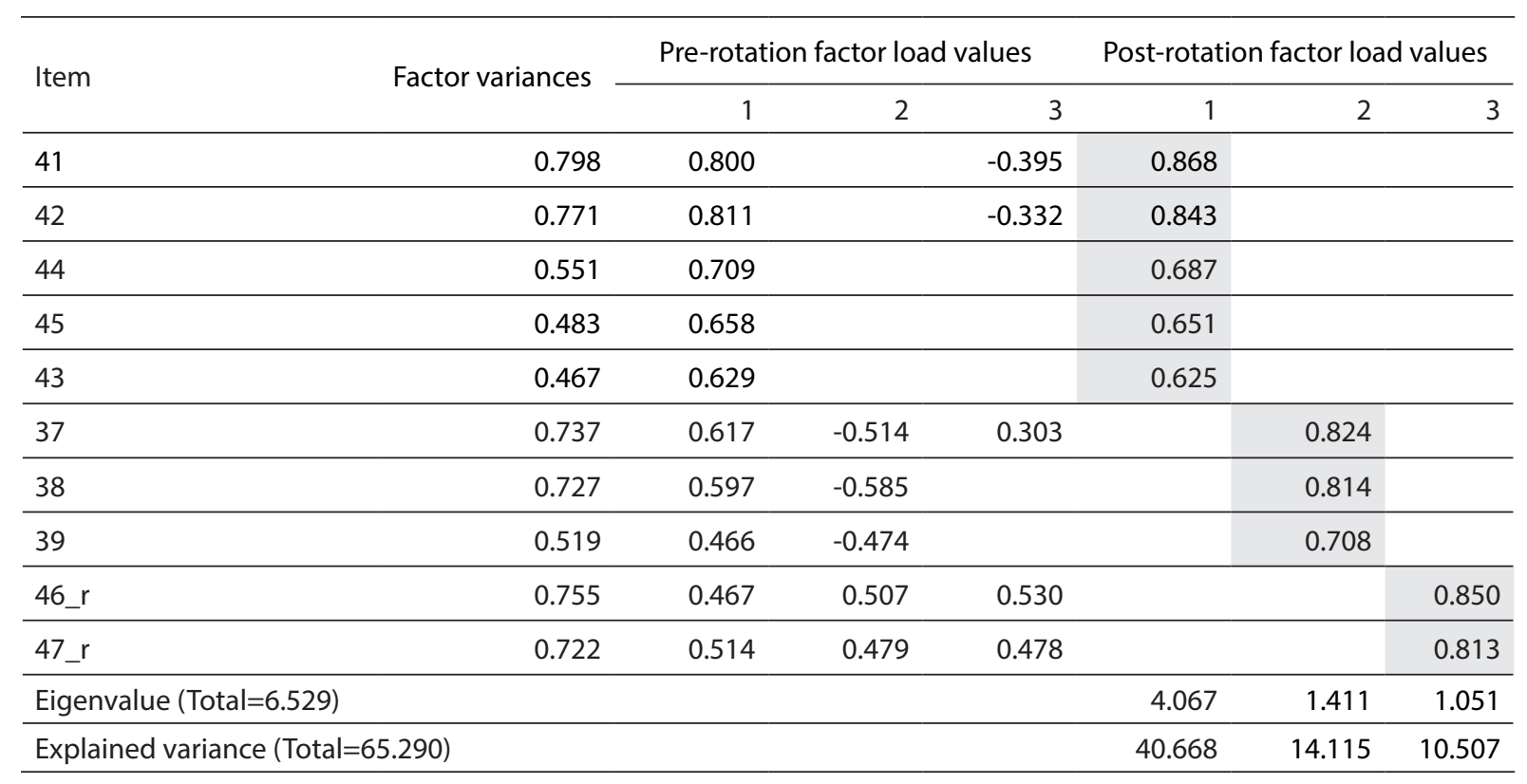




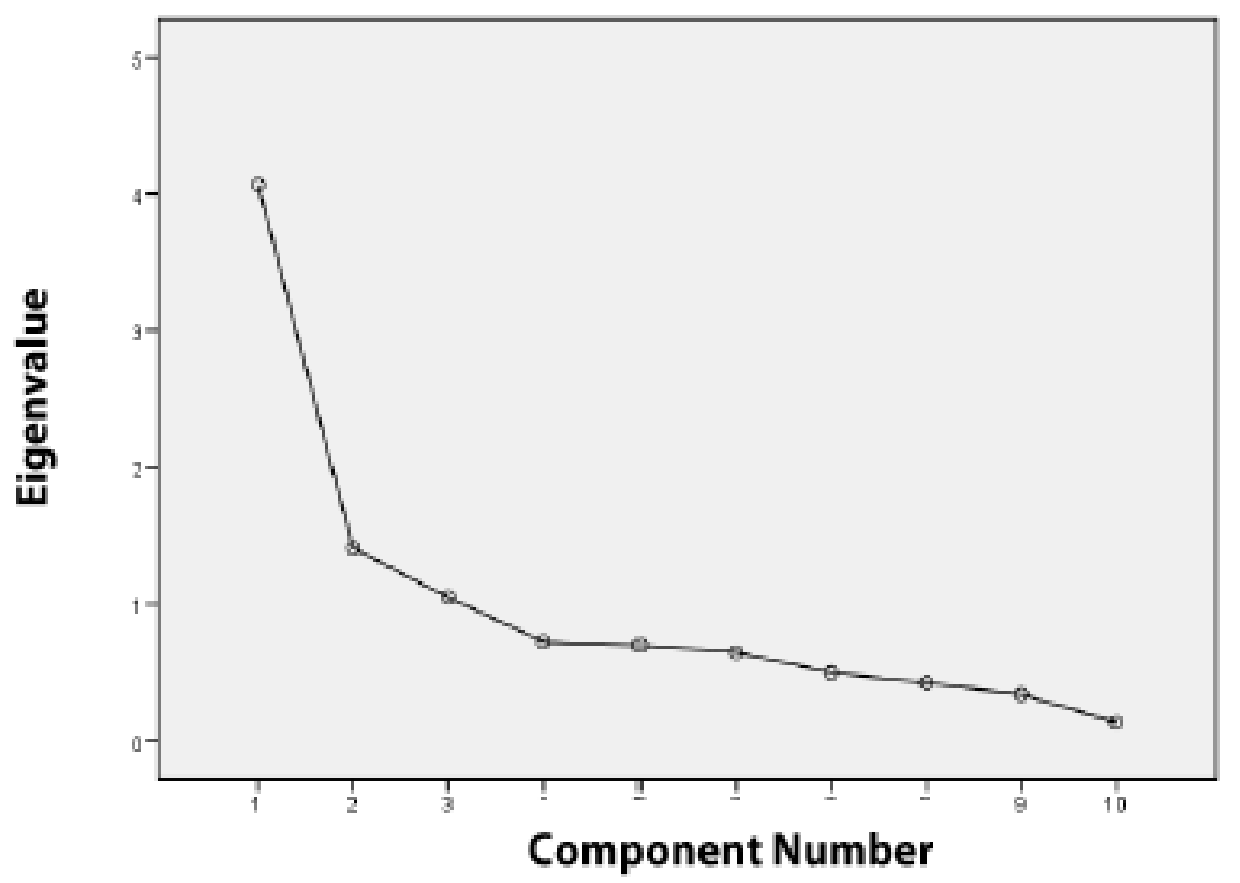

Figure 18. Institution TP second EFA scree plot

The analysis results showed that the eigenvalue of the first factor of the three-factor scale was 4.067 and the variance explained was $40.668 \%$, the eigenvalue of the second factor was 1.411 and the variance explained was $14.115 \%$, and the eigenvalue of the third factor was 1.051 and the variance explained was $10.507 \%$. The total eigenvalue of the scale was 6.529 and the total variance explained was $65.290 \%$. This result suggests that the variance explained by the scale adequately explained the quality that was measured. In addition, the factor structure of the original scale exhibited a similar structure among Turkish students. It was found that all items except Item 40 in the Turkish form constituted the same factors within the same cluster as in the original scale. In the original scale, the first factor and third factors represented institution connectedness, which made up the sub-dimensions of institution TP, while the second factor represented institution availability. The results showed that the factor structure in the original scale showed a similar structure among Turkish students and that the item-factor structure in the Turkish form of the institution TP scale was similar to the original form.

\section{CFA Results}

The structure of the TP scale, which consisted of 35 items, 3 factors (teacher, peer and institution TP) and two sub-factors (availability and connectedness) under each factor were tested with CFA. CFA was performed with first and second order analyses. The first order CFA tested the fitness of the model, which consisted of three factors each with two sub-factors, and 35 items associated with these factors. In the CFA, it was found that the error variable of institution TP had negative variance, the relevant variable was removed from the model, and the analysis was performed again. The first order CFA results showed that the five items in the teacher availability sub-factor of the teacher TP factor had a standard solution between 0.65 and 0.82 and the seven items in the teacher connectedness sub-factor had a standard solution between 0.36 and 0.73 . Also, the standard solutions of the six items in the peer availability sub-factor of the peer TP factor ranged from 0.62 to 0.81 , and the standard solutions of the six items in the peer connectedness sub-factor ranged from 0.62 to 0.90 . Finally, the three items in the institution availability sub-factor of the institution TP factor ranged from 0.54 to 0.82 , the seven items in the institution connectedness sub-factor were found to range between 0.34 and 0.92 , and all load values were statistically significant $(\mathrm{p}<0.001)$. It was concluded that all the items in the factors were significant for their factors. 


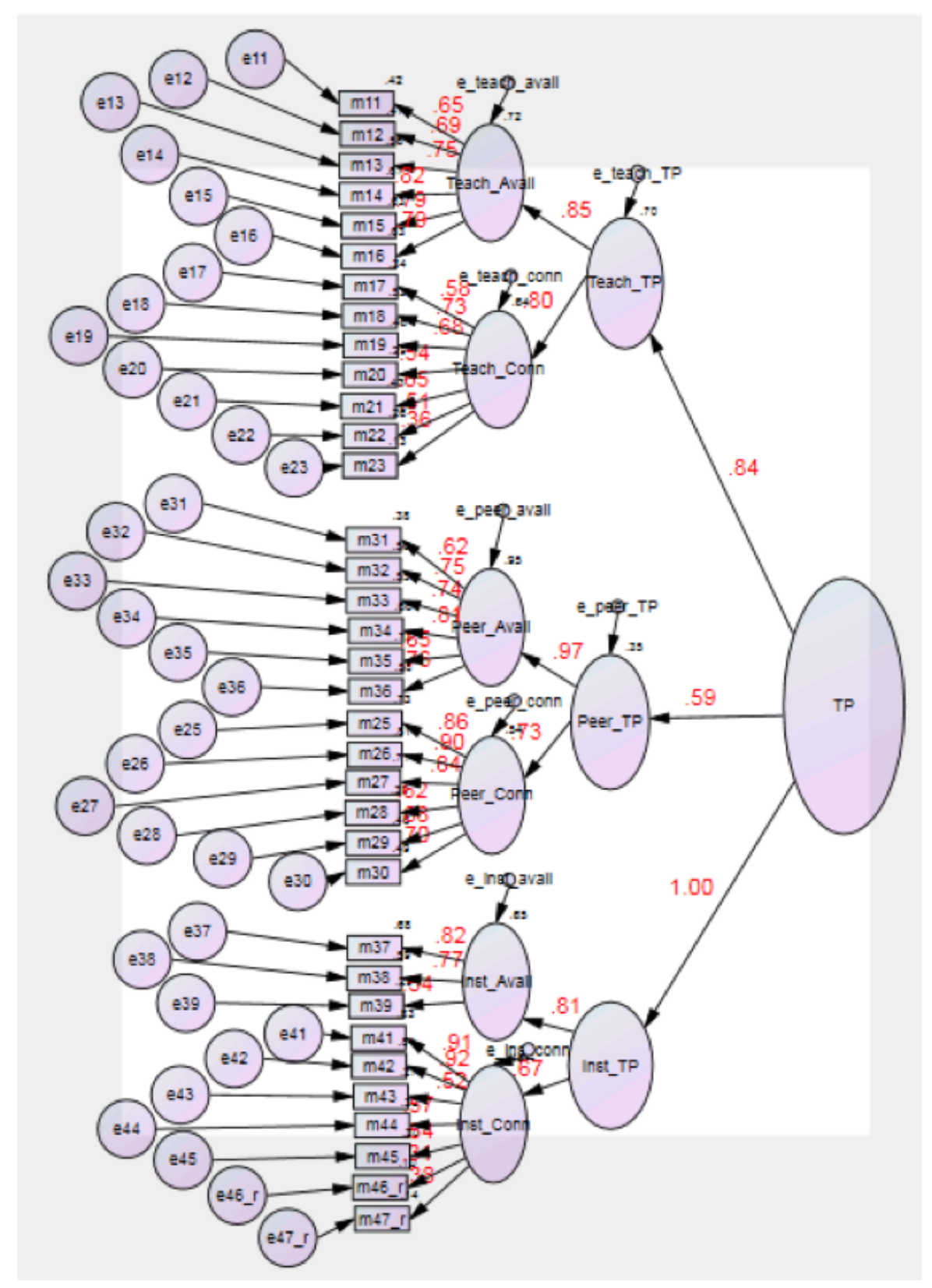

Figure 19. CFA results standard solution after modification

After standard solutions, $t$ values between the factors and items were examined. The $t$ values were found to be between 14.691 and 19.099 for the items in the teacher availability sub-factor and between 6.216 and 6.960 for the items in the teacher connectedness sub-factor of the teacher TP factor; between 12.962 and 18.043 for the items in the peer availability sub-factor and between 15.254 and 25.631 for the items in the peer connectedness sub-factor of the peer TP factor; and between 10.407 and 14.565 for the items in the institution availability sub-factor and between 5.269 and 8.189 for the items in the institution connectedness sub-factor of the institution TP factor. Also, $\mathrm{R}^{2}$ values of the items ranged between 0.099 and 0.950 and these values were significant at the 0.01 level. This standard solution indicated that $t$ and $\mathrm{R}^{2}$ values were significant for the factors and the scale to which 35 items belonged, and that they were also statistically significant since there were no red arrows for the t values (Joreskog \& Sorbom, 1996).

The fit indices of the TP scale were estimated as $X^{2}(552, n=467)=1686.527(\mathrm{p}<0.001), X^{2} / \mathrm{sd}=3.055$ RMSEA $=0.066, \mathrm{CFI}=0.863$; NFI $=0.811$, NNFI $(\mathrm{TLI})=0.844$ and $\mathrm{IFI}=0.864$. When the fit indices of the TP scale were compared with the fit indices recommended by Schermelleh-Engel, Moosbrugger and Muller 
(2003), they were considered acceptable for RMSEA and very close to acceptable values (minimum fit) for $\mathrm{X}^{2} / \mathrm{sd}$. However, the CFI, NFI, NNFI and IFI fit indices were below the acceptable values. As a result, the factor structure presented a minimum fit to the determined model.

\section{Criterion Validity}

The relationship between TP perceptions and personality traits, which is a criterion for TP, was examined in order to determine the criterion validity of the Turkish-translated version of the TP scale. First, the TIPI, which was developed by Rammstedt and John (2007) and adapted for use in Turkish by Horzum et al. (2017), was administered to 467 students in the sample simultaneously with the TP scale. After that, Pearson's correlation analysis was performed between the scores obtained from this scale and TP perceptions. The relationship between the variables is presented in Table 11 .

Table 11. Pearson's correlation test showing the relationship between personality traits and TP

\begin{tabular}{|c|c|c|c|c|c|c|c|c|}
\hline & 1 & 2 & 3 & 4 & 5 & 6 & 7 & 8 \\
\hline 1. Openness to experience & 1 & $-0.103^{*}$ & $0.240^{* *}$ & 0.083 & $0.268^{* *}$ & $0.172^{* *}$ & $0.097^{*}$ & $0.109^{*}$ \\
\hline 2. Neuroticism & & 1 & -0.090 & $-0.121^{*}$ & $-0.224^{* *}$ & $-0.172^{* *}$ & $-0.121^{*}$ & $-0.112^{*}$ \\
\hline 3. Conscientiousness & & & 1 & $0.227^{* *}$ & $0.438^{* *}$ & $0.250^{* *}$ & $0.279^{* *}$ & $0.199^{* *}$ \\
\hline 4. Agreeableness & & & & 1 & $0.148^{* *}$ & $0.130^{* *}$ & $0.201^{* *}$ & $0.183^{* *}$ \\
\hline 5. Extraversion & & & & & 1 & $0.269^{* *}$ & $0.298^{* *}$ & $0.207^{* *}$ \\
\hline 6. Teacher TP & & & & & & 1 & $0.412^{* *}$ & $0.621^{* *}$ \\
\hline 7. Peer TP & & & & & & & 1 & $0.476^{* *}$ \\
\hline 8. Institution TP & & & & & & & & 1 \\
\hline
\end{tabular}

${ }^{*} p<0.05 ;{ }^{* *} p<0.01$

As can be seen in Table 11, there was a significant and positive correlation between teacher TP and openness to experience $(r=0.172 ; \mathrm{p}<0.01)$, conscientiousness $(\mathrm{r}=0.250 ; \mathrm{p}<0.01)$, agreeableness $(\mathrm{r}=0.130 ; \mathrm{p}<0.01)$ and extraversion $(\mathrm{r}=0.269 ; \mathrm{p}<0.01)$ personality traits at the 0.01 level. However, teacher TP was significantly and negatively correlated with neuroticism personality trait $(\mathrm{r}=-0.172 ; \mathrm{p}<0.01)$ at the 0.01 level. While peer TP was significantly and positively correlated with openness to experience personality trait at the 0.05 level $(\mathrm{r}=$ 0.097; $\mathrm{p}<0.05)$, it was negatively correlated with neuroticism personality trait at the same level $(r=-0.121$; $\mathrm{p}<0.05)$. Peer TP was also significantly and positively correlated with conscientiousness $(r=0.279 ; \mathrm{p}<0.01)$, agreeableness $(r=0.201 ; \mathrm{p}<0.01)$ and extraversion $(r=0.298 ; \mathrm{p}<0.01)$ personality traits at the 0.01 level. Similar to peer TP, institution TP was significantly and positively correlated with openness to experience personality trait at the 0.05 level $(r=0.109 ; \mathrm{p}<0.05)$, but it was negatively correlated with neuroticism personality trait at the same level $(\mathrm{r}=-0.112 ; \mathrm{p}<0.05)$. In addition, institution TP was significantly and positively correlated with conscientiousness $(r=0.199 ; \mathrm{p}<0.01)$, agreeableness $(r=0.183 ; \mathrm{p}<0.01)$ and extraversion $(r=0.207 ; \mathrm{p}<0.01)$ personality traits at the 0.01 level.

In summary, the results showed that all the personality traits were correlated with perceptions of the three types of TP. Also, as neuroticism personality trait decreased, or in other words, as emotional stability increased and openness to experience, conscientiousness, agreeableness and extraversion increased, there was an increase in perceptions of teacher TP, peer TP and institution TP. These results provided evidence for the criterion validity of the scale. 


\section{Results for Reliability}

In order to estimate the reliability of the Turkish adapted version of the TP scale, a reliability analysis was performed for the items about the teacher, peer and institution TP. Cronbach's $\alpha$ values obtained for each dimension are given in Table 12.

Table 12. Reliability of the Turkish adapted version of the TP scale

\begin{tabular}{ccc}
\hline Scale & Number of Items & a value \\
\hline Teacher TP & 13 & 0.875 \\
Peer TP & 13 & 0.923 \\
Institution TP & 11 & 0.841 \\
\hline
\end{tabular}

Kline (1999, p. 15) states that the acceptable Cronbach's $\alpha$ reliability coefficient should be at least 0.7 for a good test. As can be seen in Table 12 is examined, the teacher, peer and institution TP scales included in the Turkish adapted version of the TP scale had all high reliability (teacher TP Cronbach's $\mathrm{a}=0.875$, peer TP Cronbach's $\mathrm{a}=0.923$ and institution TP Cronbach's $\alpha=0.841$ ). The results of the validity and reliability analyzes showed that the TP scale could be used as a valid and reliable instrument for measuring the TP levels of university students.

\section{Multiple Linear Regression Analysis Results}

In this study, multiple linear regression analysis was conducted to investigate whether teacher, peer and institution TP, extraversion, agreeableness, conscientiousness, neuroticism and openness to experience personal traits, age, sex and distance learning experience predicted perceived learning. The analysis assumptions were met. Field (2013) noted that when categorical variables are included in the model in regression analysis, all other variables associated with these variables should also be included in analysis by "forced entry" method. For this reason, multiple variables were included in the model by "forced entry" method. Multiple linear regression analysis results are given in Table 13.

Table 13. Results of standard multiple regression analysis for predicting perceived learning

\begin{tabular}{|c|c|c|c|c|c|}
\hline Independent variable & B & SH Beta & $\beta$ & $\mathrm{t}$ & $p$ \\
\hline \multicolumn{6}{|c|}{ Model $\left(\mathrm{R}=0.57 ; R^{2}=0.32 ; \Delta R^{2}=0.29 ; \mathrm{F}_{(11,248)}=10.78 ; p<0.01\right)$} \\
\hline \multirow{2}{*}{ Constant } & & \multirow{2}{*}{3.07} & & \multirow{2}{*}{5.29} & \multirow{2}{*}{$0.00^{*}$} \\
\hline & $(10.17 ; 22.25)$ & & & & \\
\hline \multirow{2}{*}{ Teacher TP } & 0.02 & \multirow{2}{*}{0.05} & \multirow{2}{*}{0.03} & \multirow{2}{*}{0.35} & \multirow{2}{*}{0.73} \\
\hline & $(-0.07 ; 0.11)$ & & & & \\
\hline \multirow{2}{*}{ Peer TP } & -0.02 & \multirow{2}{*}{0.04} & \multirow{2}{*}{-0.03} & \multirow{2}{*}{-0.40} & \multirow{2}{*}{0.69} \\
\hline & $(-0.09 ; 0.06)$ & & & & \\
\hline \multirow{2}{*}{ Institution TP } & 0.36 & \multirow{2}{*}{0.05} & \multirow{2}{*}{0.49} & \multirow{2}{*}{7.01} & \multirow{2}{*}{$0.00^{*}$} \\
\hline & $(0.26 ; 0.46)$ & & & & \\
\hline \multirow{2}{*}{ Extraversion } & 0.28 & \multirow{2}{*}{0.17} & \multirow{2}{*}{0.10} & \multirow{2}{*}{1.64} & \multirow{2}{*}{0.10} \\
\hline & $(-0.06 ; 0.62)$ & & & & \\
\hline \multirow{2}{*}{ Agreeableness } & 0.22 & \multirow{2}{*}{0.16} & \multirow{2}{*}{0.07} & \multirow{2}{*}{1.36} & \multirow{2}{*}{0.17} \\
\hline & $(-0.10 ; 0.54)$ & & & & \\
\hline \multirow{2}{*}{ Conscientiousness } & 0.05 & \multirow{2}{*}{0.17} & \multirow{2}{*}{0.02} & \multirow{2}{*}{0.29} & \multirow{2}{*}{0.77} \\
\hline & $(-0.29 ; 0.39)$ & & & & \\
\hline
\end{tabular}




\begin{tabular}{|c|c|c|c|c|c|}
\hline Neuroticism & $\begin{array}{r}-0.16 \\
(-0.47 ; 0.14)\end{array}$ & 0.16 & -0.06 & -1.05 & 0.30 \\
\hline Openness to experience & $\begin{array}{r}0.03 \\
(-0.30 ; 0.37)\end{array}$ & 0.17 & 0.01 & 0.19 & 0.85 \\
\hline Age & $\begin{array}{r}-0.02 \\
(-0.16 ; 0.12)\end{array}$ & 0.07 & -0.01 & -0.24 & 0.81 \\
\hline Sex & $\begin{array}{r}0.99 \\
(-0.11 ; 2.10)\end{array}$ & 0.56 & 0.10 & 1.77 & 0.08 \\
\hline DE experience & $\begin{array}{r}0.22 \\
(-0.79 ; 1.23)\end{array}$ & 0.51 & 0.02 & 0.43 & 0.67 \\
\hline
\end{tabular}

As can be seen in Table 13, the regression analysis results showed that the predictive variables explained $29 \%$ of the perceived learning levels of the learners. Institution TP $(b=0.36 ; \beta=0.49 ; t=7.01 ; p<0.01)$ was a significant predictor of perceived learning. Beta value indicated that perceived learning increased with increasing institution TP. In other words, it showed that learners' perceived learning levels would increase as their perceptions of school or institution TP increased. However, teacher TP $(b=0.02 ; \beta=0.03 ; t=0.35$; $p>0.05)$, peer TP $(b=-0.02 ; \beta=-0.03 ; t=-0.40 ; p>0.05)$; having personality traits of extraversion $(b=0.28$; $\beta=0.10 ; t=1.64 ; p>0.05)$, agreeableness $(b=0.22 ; \beta=0.07 ; t=1.36 ; p>0.05)$, conscientiousness $(b=0.05$; $\beta=0.02 ; t=0.29 ; p>0.05)$, neuroticism $(b=-0.16 ; \beta=-0.06 ; t=-1.05 ; p>0.05)$, or openness to experience $(b=0.03 ; \beta=0.01 ; t=0.19 ; p>0.05)$; age $(b=-0.02 ; \beta=-0.01 ; t=-0.24 ; p>0.05) ; \operatorname{sex}(b=0.99 ; \beta=0.10 ; t=1.77$; $p>0.05)$; and distance education experience $(b=0.22 ; \beta=0.02 ; t=0.43 ; p>0.05)$ variables were not significant predictors of perceived learning. In addition, when the ANOVA analysis results were examined according to the F statistics findings, it was found that $\mathrm{F}$ statistics were significant $(=10.78 ; \mathrm{p}<0.01)$. Therefore, we could suggest that the model is better than using averages as the best estimate.

In summary, the results showed that only institution TP was a significant predictor of perceived learning and none of the other variables (the learners' age; teacher and peer TP, personality traits of extraversion, conscientiousness, neuroticism, openness to experience or agreeableness; sex; or previous experience of distance education) was a significant predictor of perceived learning. Furthermore, there was a high positive correlation $(r=0.536)$ between perceived learning scores and institution TP scores of the learners in the study. This result showed that perceived learning scores would increase as institution TP increased. The institution TP of the learners in the study explained $29 \%$ of the total variance of perceived learning. According to the standardized regression coefficient $(\beta)$, the relative significance order of predictive variables on perceived learning was institution TP. Finally, the regression formula can be expressed as follows: Perceived learning $=16.21+(0.36 \times$ Institution TP $)$

\section{DISCUSSIONS AND CONCLUSION}

The aim of this study was to establish a valid and reliable Turkish version of the TP scale and to determine whether certain variables such as learners' personality structures, age, sex, distance education experiences and perceptions of TP (i.e. teacher, peer and institution TP) were significant predictors of their perceived learning. For this purpose, first of all, linguistic equivalence, EFA, CFA, validity and reliability analyzes were conducted for the scale adaptation study. EFA was considered important as it would indicate how the original scale structure would change in Turkish students. Since the TP scale consists of three basic dimensions (i.e. teacher, peer and institution TP), EFA was performed for each dimension. EFA results showed that the teacher TP scale had a three-factor structure and Factor 1 represented teacher availability while Factors 2 and 3 represented teacher connectedness. The analysis results also showed that the total eigenvalue of the scale was 7.884 , it explained $60.642 \%$ of the variance, and factor load values of the items ranged between 0.624 and 0.828 . The original version of the scale also had a three-factor structure and the corresponding items constituted the same sub-dimensions. In addition, the total eigenvalue of the original scale was 7.907, 
it explained $60.830 \%$ of the variance and factor load values of the items were between 0.452 and 0.844 (Shin, 2001). Although there are cultural differences between the expressions in the original version and the Turkish adapted version of the scale, the two versions could be considered equal because of the three-factor structure, total eigenvalue, similarity of the explained variances, and even higher factor loads of the items in the Turkish adapted version than the original scale.

According to EFA results for the Turkish adapted version of the peer TP scale, the scale had two factors, Factor 1 represented peer connectedness and Factor 2 represented peer availability. Item 24 was excluded from the analysis because it had a similar factor load (factor load difference less than 0.10 ) on both factors and EFA was performed again. According to the results of the second EFA, the total value of the peer TP scale was 7.974 , it explained $66.45 \%$ of the variance and factor load values of the items ranged between 0.573 and 0.854 . The original version of the scale also had a two-factor structure and the corresponding items constituted the same sub-dimensions. In addition, the total eigenvalue of the original scale was 9.048, it explained $69.602 \%$ of the variance and factor load values of the items were between 0.564 and 0.846 (Shin, 2001). Both the Turkish adapted and original versions of the scale could be considered equal because they both had a two-factor structure, these factors represented the same sub-dimensions, and the explained variance and factor load values of the items were close to each other although the total eigenvalue was lower in the Turkish adapted version than in the original form. The fact that Item 24 was removed from the scale and EFA was performed for the second time could be the reason why the total eigenvalue was lower and the variance explained was relatively lower than the original form. Moreover, cultural differences need to be taken into account, too.

EFA results for the institution TP scale showed that the scale had a three-factor structure, Factors 1 and 3 represented institution connectedness and Factor 2 represented institution availability. In addition, the total eigenvalue of the scale was 6.905 , it explained $62.771 \%$ of the variance and factor load values of the items ranged between 0.623 and 0.853 . Similarly, the original version of the scale had a three-factor structure, but Factor 1 represented institution availability while Factors 2 and 3 represented institution connectedness. In this respect, the scale had the same structure as the original version, but the sub-dimensions of the corresponding factors differed. Also, the total eigenvalue of the original scale was 7.199, it explained $65.439 \%$ of the variance and factor load values of the items ranged from 0.573 to 0.873 (Shin, 2001). Both the Turkish adapted and original versions of the scale could be considered equal because they both had a three-factor structure and the explained variance and factor load values of the items were close to each other. However, the order of the sub-factors differed in the Turkish adapted version. As a result, although there were some differences between the Turkish version and the original version, the scale was still found to have a similar structure to the original scale. The sub-dimensions that Factors 1 and 2 were included in the original form, or in other words, the sub-dimensions that they were thought to measure, worked in a reversed way in Turkish culture. Those items that measured institution connectedness and availability were in different places. This could have been caused by cultural differences.

The fitness of the Turkish version of the scale to the model was checked by CFA. CFA results showed that the $t$ values of the items and factors in the latent variable ranged between 4.561 and $25.639, \mathrm{R}^{2}$ values were between 0.099 and 0.950 and they were significant at the 0.01 level. This standard solution suggests that all 35 items were important for their factors and the scale, and they were statistically significant since there were no red arrows in t values (Joreskog \& Sorbom, 1996). These results indicated that the indices of the variables in the model could be examined. According to the CFA results, the scale had $X^{2}(551, n=467)$ $=1685.608(\mathrm{p}<0.001) ; \mathrm{X}^{2} / \mathrm{s} \mathrm{d}=3.059$ RMSEA=0.066; CFI=0.863; NFI $=0.811 ; \mathrm{NNFI}(\mathrm{TLI})=0.843$ and IFI=0.864 fit indices. When the fit indices of the TP scale were compared with the fit indices recommended by Schermelleh-Engel, Moosbrugger and Muller (2003), they were acceptable for RMSEA and very close to acceptable values (minimum fit) for $\chi^{2} / s d$. However, the CFI, NFI, NNFI and IFI fit indices were below the acceptable values. As a result, the factor structure presented a minimum fit to the determined model.

In order to determine the criterion validity of the Turkish adapted version of the TP scale, the relationship between TP perceptions and personality traits, which is a criterion for TP, was examined. For this purpose, Pearson's correlation analysis was performed between the scores obtained from the TIPI and TP perceptions. According to the results, all personality traits were associated with perceptions about the three types of 
TP. In addition, as neurotic personality trait decreased, or in other words, emotional stability, openness to experience, conscientiousness, agreeableness and extraversion increased, perceptions of teacher, peer and institution TP increased. These results provided evidence for the criterion validity of the scale.

Once the linguistic equivalence, face validity, content validity, criterion validity and construct validity of the Turkish adapted version of the TP scale were ensured, a reliability analysis was performed to estimate its reliability. Cronbach's alpha internal consistency coefficients were examined for consistency for the reliability of the scale. The first dimension of the scale, "teacher TP", had a reliability score of 0.875 ; the second dimension, "peer TP", had a reliability score of 0.923 ; and the third dimension, "institution TP", had a reliability score of 0.841 . We could suggest that these values indicated high internal consistency, in other words, they would produce consistent data. In terms of the internal consistency coefficients of the original version of the scale, the first dimension had a reliability score of 0.88 , the second dimension had a reliability score of 0.94 , and the third dimension had a reliability score of 0.85 (Shin, 2001). Therefore, it was concluded that the internal consistency coefficients of the Turkish adapted version were close to the values obtained in the original version of the scale.

Based on these findings, the TP scale, developed by Shin (2001) and adapted for use in Turkish, was found to have item-factor fit and a structure similar to the original form. On the other hand, some values were found to be lower than the original form. This result might have been caused by the fact that the original form was administered after it was translated from English to Korean, but in this study it was translated from English to Turkish. Also, another reason could be cultural differences of the respondents and, therefore, differences in their evaluation of the scale items.

In this study, multiple linear regression analysis was conducted to investigate whether certain variables (the learners' personality structures, age, sex, distance education experiences and perceptions of teacher, peer and institution TP) were significant predictors of their perceived learning. The results showed that only institution TP was a significant predictor of perceived learning and none of the other variables (the learners' age; teacher and peer TP, personality traits of extraversion, conscientiousness, neuroticism, openness to experience or agreeableness; sex; or previous experience of distance education) was a significant predictor of perceived learning. The institution TP of the learners in the study explained $29 \%$ of the total variance of perceived learning. According to the standardized regression coefficient $(\beta)$, the relative significance order of predictive variables on perceived learning was institution TP. This indicates that the distance learner's relationship with the institution is important. In her study, Shin (2001) showed that institution TP predicted all the variables (i.e. learning achievement, satisfaction, and intent-to-persist) and, therefore, it was important. Furthermore, Shin and Chan (2004) stated that there was a significant relationship between students' perceptions of institution presence and satisfaction, intent-to-persist in the course of study, and learning outcomes. In this respect, the findings of this study are supported by the findings in the literature. In addition, as Shin (2001) suggested, considering the fact that institution TP is more likely to be perceived in the context of student support services, students' access to the services and information they need (institution availability) and developing a sense of belonging (institution connectedness) by seeing themselves as a part of the institution could increase their level of perceived learning. By its very nature, distance education requires the learner to have the ability to self-manage his or her learning process (learner autonomy). This is also an important component of transactional distance. In distance learning, for students with lower learner autonomy and in need of more support services, the institution could decrease the perception of transactional distance that learners could feel by providing more effective dialogue and communication processes. As this situation increases sense of connectedness to the institution, this could positively affect dropout rates, which is one of the major problems in distance learning, and thus improve students' beliefs and feelings about their learning.

The sample of this study, the pedagogical formation training group, was provided with support via Facebook, with e-mail, on IP phone and face-to-face. The accessibility of the application in this study could be associated with the higher perception of institution TP among the respondents. In fact, the positive effect of this situation on perceived learning is an expected result. 
In addition, the results showed that personality structures were not a significant predictor of perceived learning. Since personality structures mostly express the mental and spiritual characteristics of an individual that distinguish him or her from others (Horzum, Ayas \& Padır, 2017), these mental and spiritual characteristics are not expected to be directly correlated with perceived learning, whereas they are expected to be correlated with perceptions where psychological factors come into prominence such as TP (Horzum, 2015). Similarly, in this study, personality structures were correlated with TP, where psychological basis was prominent, but they were not significantly correlated with perceived learning, where cognitive processes normally come into prominence. Finally, the results also showed that sex and age, which are demographic characteristics, had no significant effect on perceived learning.

\section{RECOMMENDATIONS}

As a result of this study, a valid and reliable Turkish version of the TP scale was generated. The scale was used as an independent variable in the study. In future studies, TP and its dimensions to be measured with this scale could be considered as dependent variables, and demographic characteristics such as age, sex and previous experience of distance education could be examined by variables such as learners' majors, departments, professions or experiences. Similarly, future research could investigate TP and its sub-dimensions in association with different learning outcomes apart from perceived learning such as achievement, satisfaction, motivation, intent-to-persist and willingness.

This study investigated TP perceptions in a hybrid model of synchronous and asynchronous activities in a one-semester distance education application. Future research could investigate learners' TP perceptions in fully distance, fully synchronous, fully asynchronous or hybrid learning models and in different learning environments (e.g. LMS platforms, MOOCs, etc.). In addition, longitudinal studies could also investigate TP.

The results of this study showed that institution TP was the only variable that predicted the perceived learning of the learners. We could suggest that this finding supports the importance of institution TP, which was mentioned previously. Therefore, institutions or service providers offering distance education services should be aware of the impact of institution TP, develop an effective distance education student support service and ensure that services are recognized by their students (Shin, 2003). By working in different contexts and with different samples, future research could examine whether the scale would yield a similar structure under those conditions.

Finally, TP perceptions could be investigated with respect to the student support services of universities. The relationship between the types of support services offered by universities and learners' perceptions of institution TP can be examined. Similarly, the relationship between teachers TP as perceived by learners and their various demographic characteristics and the academic and administrative support provided by the institution to the teacher can be examined. Determining the relationships between the reasons for the results to be obtained in such studies and the variables in consideration could help increase institution TP perceptions of both current and prospective learners, reduce drop-out rates, ensure more effective learning and increase the quality and sustainability of the services offered.

Author's Note: This study was derived from an MSc thesis supervised by Dr. Mehmet Barıs HORZUM in Sakarya University Computer and Instructional Technology Department. 


\section{BIODATA and CONTACT ADDRESSES of AUTHOR}

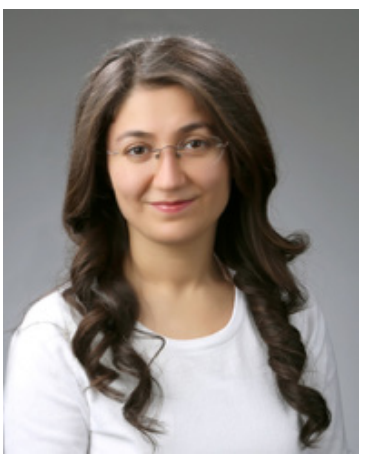

Gulten KARTAL has been working as an educational technologist in several public schools of Ministry of National Education since 2006 has gained a BS degree in Computer Education and Instructional Technology Department at Ege University. She had her master degrees both in Computer and Instructional Technology department from Sakarya University and Distance Education department from Anadolu University. She is currently a doctoral candidate in the department of Distance Education in Anadolu University. Her research interests are cultural issues, presence and instructional design in open and distance learning.

Gulten KARTAL

Address: Anadolu University, Graduate School of Social Sciences,

Department of Distance Education, Eskisehir, TURKEY

Phone: +902222116317

Email: gultenkartal@gmail.com

\section{REFERENCES}

Albayrak, E., Gungoren, O. C., Horzum, M. B. (2014). Algilanan ogrenme olceginin Turkceye uyarlamasi. Ondokuz Mayis Universitesi Egitim Fakultesi Dergisi, 33(1), 1-27.

Bacon, D. R. (2016). Reporting actual and perceived student learning in education research. Journal of Marketing Education, 38(1), 3-6.

Bahcekapili, E. \& Karaman, S. (2015). Uzaktan egitimde kisilik ozellikleri ve akademik basari: Bir literatur incelemesi. Journal of Instructional Technologies \& Teacher Education, 4(3), 26-34.

Bayram, S., Deniz, L. \& Erdogan, Y. (2008). The role of personality traits in web based education. The Turkish Online Journal of Educational Technology - TOJET, 7(2), 41-50.

Belaja, K., Boon Sai, G. T. \& Wei Lin, A. L. (2012). Effects of the lecturer's transactional presence towards learners' intrinsic motivation in learning english as a second language through distance education. Malaysian Journal of Distance Education 14(1), 77-97.

Bhagat, K. K., Wu, L. Y., \& Chang, C. Y. (2019). The impact of personality on students' perceptions towards online learning. Australasian Journal of Educational Technology, 35(4), 98-108. https://doi. org/10.14742/ajet.4162

Busari, A. O. (2017). The relationship between personality types, learning styles, motivation, self-esteem and academic stress among distance learners in ibadan study center. International Journal of Innovation and Applied Studies, 19(4), 850-862.

Buyukozturk, S. (2011). Sosyal bilimler icin veri analizi el kitabi istatistik, arastirma deseni SPSS uygulamalari ve yorum (13th ed.). Ankara: Pegem Akademi

Caspi, A. \& Blau, I. (2008). Social presence in online discussion groups: testing three conceptions and their relations to perceived learning. Social Psychology of Education, 11(3), 323-346.

Field, A. (2013). Discovering statistics using IBM SPSS statistics (4th ed.). Los Angeles: SAGE Publications.

Garrison, D. R., Anderson, T., \& Archer, W. (2000). Critical inquiry in a text-based environment: Computer conferencing in higher education. The Internet and Higher Education, 2(2-3), 87-105.

Gosling, S. D., Rentfrow, P. J., Swann Jr, W. B. (2003). A very brief measure of the Big-Five personality domains. Journal of Research in Personality, 37(6), 504-528. Retrieved from http://www. sciencedirect.com/science/article/pii/S0092656603000461

Horzum, M. B. (2015). Online learning students perceptions community of inquiry based on learning outcomes and demographic variables. Croatian Journal of Education, 17(2), 535-567.

Horzum, M. B., Ayas, T.,\& Padir, M. A. (2017). Bes Faktor Kisilik Olceginin Turk Kulturune Uyarlanmasi. Sakarya University Journal of Education, 7(2), 398-408. 
Joreskog, K. \& Sorbom, D. (1996). LISREL 8: Structural equation modeling with the SIMPLIS command language. Chicago: Scientific Software International/Erlbaum

Kaiser, H. F. (1974). An index of factorial simplicity. Psychometrika, 39 (1), 31-36. Retrieved from http:// jaltcue.org/files/articles/Kaiser1974_an_index_of_factorial_simplicity.pdf

Karasar, N. (2010). Bilimsel arastirma yontemi (21th ed.). Ankara: Nobel Yayin.

Kline, P. (1999). The handbook of psychological testing (2nd ed.). London: Routledge. Retrieved from https:// books.google.com.tr/books?hl=tr\&lr=\&id=JggVAgAAQBAJ\&oi=fnd\&pg=PP1\&dq=The+handbook+of+psychological+testing\&ots=KOkoM2gqsu\&sig=buVcunwXcXHhmiEW0HDyf29JMvs\&redir_esc $=\mathrm{y} \# \mathrm{v}=$ onepage $\& \mathrm{q}=$ reliability $\& \mathrm{f}=$ false

Moore, M. G. (1997). Theory of transactional distance. In D. Keegan (Ed.), Theoretical Principles of Distance Education (pp. 22-38). Routledge.

Naylor, L. A. \& Wilson, L. A. (2009). Staying connected: MPA student perceptions of transactional presence. Journal of Public Affairs Education, 15(3), 317-331. doi: 10.1080/15236803.2009.12001563

Poellhuber, B., Racette, N. \& Chirchi, M. (2012). De la présence dans la distance par la visioconférence Web. Revue internationale des technologies en pédagogie universitaire / International Journal of Technologies in Higher Education, 9 (1-2), 63-77. https://doi.org/10.7202/1012903ar

Rammstedt, B. \& John, O. P. (2007). Measuring personality in one minute or less: A 10-item short version of the Big Five Inventory in English and German. Journal of Research in Personality, 41(1), 203212.

Randler, C., Horzum, M. B. \& Vollmer, C. (2014). The influence of personality and chronotype on distance learning willingness and anxiety among vocational high school students in Turkey. The International Review of Research in Open and Distributed Learning, 15(6). https://doi.org/10.19173/irrodl. v15i6.1928

Rovai, A. P., Wighting, M. J., Baker, J. D., Grooms, L. D. (2009). Development of an instrument to measure perceived cognitive, affective, and psychomotor learning in traditional and virtual classroom higher education settings. Internet and Higher Education, 12(1), 7-13. Retrieved from http://www. sciencedirect.com/science/article/pii/S109675160800064X

Samuel, A. (2015). Faculty perception of "presence" in the online environment. Paper presented at the Adult Education Research Conference, Manhattan, Kansas, USA. Retrieved from http://newprairiepress. org/aerc/2015/papers/47

Schermelleh-Engel, K., Moosbrugger, H. \& Muller, H. (2003). Evaluating the fit of structural equation models: Tests of significance and descriptive goodness-of-fit measures. Methods of Psychological Research Online, 8(2), 23-74. Retrieved from https://www.researchgate.net/publication/251060246_ Evaluating_the_Fit_of_Structural_Equation_Models_Tests_of_Significance_and_Descriptive_ Goodness-of-Fit_Measures

Siddiquei, N. L. \& Khalid, R. (2018). The relationship between personality traits, learning styles and academic performance of e-learners. Open Praxis, 10(3). https://openpraxis.org/index.php/ OpenPraxis/article/view/870/485

Shin, N. (2001). Beyond interaction: Transactional presence and distance learning (Doctoral dissertation, The Pennsylvania State University, USA). Retrieved from https://search.proquest.com/ docview/304718633?accountid $=13654$

Shin, N. (2003). Transactional Presence as a Critical Predictor of Success in Distance Learning. Distance Education, 24 (1), 69-86.

Shin, N. \& Chan, K. Y. (2004). Direct and indirect effects of online learning on distance education. British Journal of Educational Technology, 35(3), 275-288.

Starr-Glass, D. (2013). From connectivity to connected learners: Transactional distance and social presence. In C. Wankel \& P. Blessinger (Eds.), Increasing Student Engagement and Retention in e-Learning Environments: Web 2.0 and Blended Learning Technologies (pp. 113-143). UK: Emerald Group Publishing 